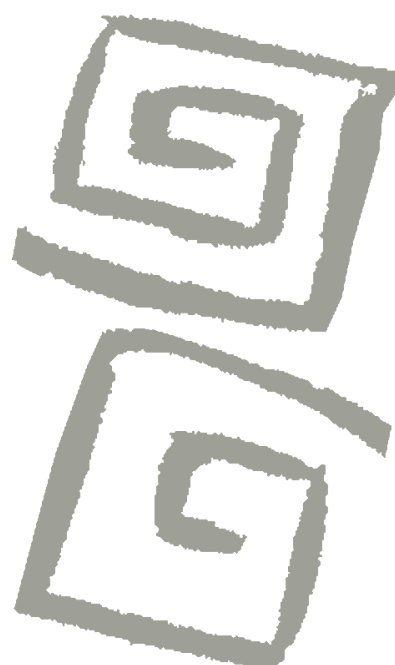

Máquinas y arte-sanos

\title{
Machines and artisanal health workers
}

${ }^{1}$ Doctor en Salud Colectiva. Director, Instituto de Salud Colectiva, Universidad Nacional de Lanús, Buenos Aires, Argentina. $\triangle$ iD
RESUMEN Este trabajo discute los modelos dominantes y las tensiones, al interior del campo de la salud, entre la concepción del cuerpo humano (máquina); el proceso de trabajo médico (modelos industriales o artesanales); las institucionalidades (hospitales y centros de salud) y los principales agentes (corporación médica y complejo médico industrial). El análisis se contextualiza en EEUU desde fines del siglo XIX a la actualidad. Se discuten dimensiones económico-políticas, ideológico-culturales y científico-técnicas, que atraviesan la historicidad del campo. El propósito es elucidar cómo se viene transformando el campo de la salud, y qué peso tiene la razón instrumental y el capital financiero en ese proceso, en detrimento de lo relacional.

PALABRAS CLAVES Cuerpo Humano; Hospitales; Centros de Salud; Historia; Medicalización; Robótica.

ABSTRACT This work discusses the dominant models and tensions within the health field regarding the conceptualization of the human body (as a machine), the process of health work (industrial and artisanal models), institutions (hospitals and health centers) and primary agents (the medical corporation and the medical industrial complex). The context of analysis is the United States from the end of the 19th century to the present. Economic-political, ideological-cultural, and scientific-technical dimensions are discussed, which permeate the historicity of the field. The purpose is to illustrate how the health field has transformed over time, as well as the role instrumental reason and financial capital has played in this process, to the detriment of relational aspects.

KEY WORDS Human Body; Hospitals; Health Centers; History; Medicalization; Robotics. 


\section{INTRODUCCIÓN}

\begin{abstract}
El sueño fue que la razón, a través de las artes y las ciencias, liberaría a la humanidad de la escasez y los caprichos de la naturaleza, de la ignorancia y la superstición, de la tiranía y, sobre todo, de las enfermedades del cuerpo y el espíritu. Paul Starr ${ }^{(1)}$
\end{abstract}

Entre los siglos XVIII y XX ocurrieron una sucesión de inventos y desarrollos tecnológicos que dieron lugar a nuevos modelos productivos y organizativos que conformaron primero la revolución industrial y luego la revolución tecnológica. Desde entonces, se formaron nuevos "ideales" en distintos campos de conocimientos que impactaron en los procesos de trabajo, las formas organizativas, los desarrollos institucionales, la construcción social de la realidad y los procesos relacionales $2,3,4,5,6)$. Esto se tradujo tanto en la "objetividad del primer orden", establecida por la distribución de los recursos materiales y de los modos de apropiación de los bienes y valores socialmente escasos, como también en la "objetividad del segundo orden", bajo la forma de sistemas de clasificación, de esquemas mentales y corporales que sirvieron como matriz simbólica de las actividades prácticas, conductas, pensamientos, sentimientos y juicios de los agentes sociales ${ }^{(7)}$.

Este artículo tiene como propósito elucidar cómo se fue transformando el campo de la salud durante el siglo $\mathrm{XX}$, y qué peso tuvieron las tecnologías, en detrimento de lo relacional que quedó subordinado a la razón instrumental, en tanto lógica dominante.

Henry Sigerist encuentra que "la medicina es una de las cosas más estrechamente vinculada con el conjunto de la cultura, puesto que toda transformación en las concepciones médicas está condicionada por transformaciones en las ideas de la época" ${ }^{\prime \prime(8)}$. Es por ello que, al analizar un hospital, un centro de salud y/o un consultorio, se encuentran propuestas o búsquedas de formas organizativas de carácter taylorista, fayollista y/o fordista, sustentadas en tecnologías duras (tecnologías materiales, básicamente equipamientos). Pero, sin embargo, esas tecnologías duras ni la suma de todas ellas, constituyen una totalidad explicativa de lo que se hace $-y$, sobre todo, se debiera hacer- en cualquier institución de salud, en la que las tecnologías blandas (relaciones interpersonales basadas en vínculos y el cuidado del otro), sostienen el proceso de trabajo de tipo artesanal, el cual posee un potencial muy alto, tanto en eficacia, como en eficiencia, y en el vínculo entre trabajadores-usuarios-institución y territorios $\mathrm{s}^{(9,10,11,12,13)}$.

También se debe destacar que la complejidad de los cambios en las identidades profesionales va más allá de los avances de la ciencia médica en el último siglo. Estos ocurren en el marco de tramas de relaciones entre profesionales, Estado y comunidad, a través de distintos mecanismos que han desvirtuado el ejercicio profesional, a la vez que interfieren en poder alcanzar niveles de salud acordes al conocimiento científico; y han transformado a la salud en una mercancía, negándole su carácter de derecho ${ }^{(14,15)}$.

Por lo tanto, el análisis nos obliga a tener en cuenta tanto las condiciones de espacio y tiempo, como la articulación entre actores y estructuras, y entre lo macro y lo micro; de manera de poder entender los procesos relacionales desde un enfoque historiográfico bajo una lógica de procesos, tratando que la historia explique y no se reduzca a una secuencia lineal de hechos ${ }^{(16)}$. Por ello, el análisis comprende la historicidad del objeto de estudio, lo cual nos lleva a relacionar el problema con la historia:

Hegel y Marx nos enseñaron que el problema de la historia se confunde con la historia del problema, y que es imposible describir de manera válida un hecho que ha de tenerse en cuenta la evolución de las ideas y también la de la manera en que los hombres han representado los hechos en estudio, evolución que constituye un elemento importante de la génesis del fenómeno. Sin duda que lo inverso es también verdadero. La historia del problema es el problema de la historia; y la 
historia de las ideas no podría ser positiva si no se ligara de manera íntima con la historia de la vida económica, social y política de los hombres ${ }^{(17)}$.

La propuesta metodológica reconoce el poder hermenéutico de la reconstrucción histórica. La historia importa porque explica y nos permite entender el presente desde una perspectiva centrada en la sociedad y en los intereses de los actores ${ }^{(16)}$. Por todo ello es que nos proponemos analizar la medicina desde el siglo XVII -momento en que se consolida la idea del cuerpo humano como máquinahasta la crisis de "los sistemas de salud" en la actualidad, discutiendo cómo la singularidad del campo y los intereses de los actores influyen en los procesos de trabajo, las formas organizativas, las formas institucionales y la propia profesión médica. La intención es no replicar la historia de la medicina como un conjunto de biografías, ni como una secuencia de descubrimientos, sino entender los cambios que constituyen el trabajo médico en una profesión a través del monopolio cognitivo, los arreglos corporativos, las estrategias asociativas y el fomento de identidades grupales, solo superados en el tiempo por la propia dinámica del capitalismo a través del complejo médico industrial ${ }^{(18,19)}$.

El texto tiene siete apartados: la introducción que presenta el propósito, el problema y la metodología; el segundo que analiza la asociación del cuerpo humano con la máquina; el tercero se centra en los distintos roles del hospital desde el siglo XVII a la actualidad; el cuarto apartado analiza el Complejo Médico Industrial; el quinto aborda el impacto en los procesos de trabajo de la llegada del robot y postula la vuelta del artesano y de lo artesanal; en el sexto recuperamos la historia de los centros de salud, para interrogarnos sobre la institucionalidad que le fue negada y su capacidad potencial para definir reglas de juego y albergar al arte-sano; y por último, y a manera de cierre volvemos sobre esa ilusión que genera el progreso, y que promete grandes logros, pero que, en general, termina en desencanto ${ }^{(11,20)}$, para dejar preguntas que buscan desencadenar cinco ejes de discusión: la concepción del cuerpo y lo corporal; el tipo de trabajo en el campo; la humanización de la atención; las formas institucionales en juego; y la salud como derecho social o bien de mercado.

Las referencias empíricas se basan centralmente en EEUU por ser el país donde se desarrollaron las ideas centrales de la teoría general de la administración ${ }^{(21)}$; por haber sido sede de la gran reforma de la educación médica -Informe Flexner- a principios de siglo $\mathrm{XX}^{(22)}$; porque en el tema hospitales -tal lo observado por Henry Sigerist- recapitula en menor tiempo la historia de los hospitales en Europa ${ }^{(1)}$; por tener una atención médica centrada en seguros privados, financiamiento indicado desde las usinas del pensamiento neoliberal, a pesar de tener el sistema de salud con mayor gasto del mundo, con relación al producto bruto interno $(\mathrm{PBI})^{(23,24)}$; y porque en ese país se conformó el complejo médico industrial $^{(25)}$. Al tomar referencias empíricas de EEUU, no hacemos más que reconocer su centralidad en la "doxa"(6) que atraviesa el campo de la salud y, por lo tanto, su influencia cultural e ideológica en el desarrollo técnico-científico ${ }^{(24)}$. Así, analizaremos cómo el devenir de la medicina en EEUU es la historia dominante de la razón médica en los últimos siglos, y cómo el proceso salud/enfermedad/ atención se transformó en una cuestión de poder durante el siglo XX. Esto ubica a la Asociación Médica Americana (AMA) como actor central de dicho proceso al punto que, desde la mitad del siglo XIX, no hubo prácticamente en EEUU ningún presidente (tanto demócrata como republicano) que no haya intentado, sin éxito, una reforma de la atención médica que limitara el poder médico. Solo el complejo médico industrial, a fines del siglo XX, consiguió horadar ese poder a través de procesos masivos de medicalización ${ }^{(1)}$.

\section{EL CUERPO HUMANO COMO MÁQUINA}

Durante los siglos XVII y XVIII se origina la metáfora del cuerpo humano como máquina, idea 
que se mantiene hasta la actualidad a pesar de las evidencias científicas que la niegan.

\section{La teoría iatromecánica}

En el siglo XVII se inicia el paso de lo cualitativo a lo cuantitativo. Hasta entonces, la cuantificación en la medicina era casi inexistente ${ }^{(26,27)}$. Es durante el renacimiento y el barroco que la medicina asiste a una serie de cambios en la ciencia, que tienen repercusión en su constitución. Así, la centralidad de la máquina -fuelles, bombas y válvulasimpulsa a la fisiología ${ }^{(28)}$, el método experimental se consolida con las obras de Francis Bacon, René Descartes y Galileo Galilei, que llevan a una visión del mundo mecanizada y matemática ${ }^{(28)}$. A la vez que se construyen nuevos instrumentos como el microscopio y el termómetro, diferentes teorías intentan explicar la enfermedad, tales como la iatroquímica, la iatromecánica, el animismo y el vitalismo ${ }^{(29)}$. Esto produce duros enfrentamientos conceptuales de los que surgen las primeras sociedades científicas, que conviven con la astrología, la inquisición y la alquimia como expresiones de la razón, la religión y lo mágico. Todas compiten para explicar los modos de enfermar y de morir ${ }^{(30)}$.

La teoría iatromecánica (siglos XV y XVII) se basa en la física mecánica y concibe el cuerpo humano como máquina. Así, las partes sólidas del organismo se entienden regidas por leyes de la estática, mientras las líquidas por leyes de la hidráulica ${ }^{(29)}$. Iván Illich plantea que, en esa manera de entender el cuerpo humano, "el dolor se convirtió en una luz roja y la enfermedad en una avería mecánica"(31).

En el año 1543, se imprime la obra cumbre de la anatomía, escrita por Andreas Vesalio, con un título acorde a los tiempos De humanis corporis fabrica. Otro hito en la concepción del cuerpo como máquina, lo marca William Harvey, médico inglés, quien entre 1616 y 1618, a través de la anatomía comparada describe la circulación general de la sangre, contradiciendo las "verdades" de Galeno. El libro aparece en 1628 con el título
Exercitatio anatómica de motu cordis et sanguinis in animalibus ${ }^{(32)}$. Las 70 páginas de la publicación producen un fuerte impacto, ya que constituyen la primera aplicación de la lógica experimental en la biología. A pesar de la resistencia que generó el texto y de que el autor haya sido considerado como un loco, William Harvey instala un modelo explicativo que transciende la medicina e impacta en la biología. Esta teoría, sustentada en principios de ingeniería hidráulica, se complementa con los descubrimientos de Marcello Malpighi quien, en 1661, a través del microscopio, describe la circulación capilar en los pulmones. Harvey, con su trabajo sobre la circulación sanguínea, es el primero en involucrar a las matemáticas a través de pruebas y cálculos en el estudio del cuerpo humano ${ }^{(33,34)}$. En la misma época, Jean Pecquet y Thomas Bartholin descubren el sistema linfático, al cual el propio William Harvey se opone ${ }^{(27,33)}$. En 1748, Julien Offray de La Metrie (1709-1751) escribe El hombre máquina ${ }^{(35)}$. Ese médico francés, naturalista y empirista provoca una gran controversia al negar la existencia del alma y sostener ideas que, en el siglo siguiente, constituyeron las bases de las ideas raciales y criminológicas del positivismo.

Eran tiempos de proliferación de autómatas, lo cual expresa la asociación entre lo humano y la máquina -isomorfismo simbólico- que reinaba en el campo de la ciencia $^{(36)}$. Hasta entonces, lo humano y la máquina habían sido elementos dispares ${ }^{(37)}$.

René Descartes es uno de los primeros en aceptar la teoría de Harvey, con quien mantiene una relación intelectual ${ }^{(36)}$ y es considerado -junto a este último- cofundador de la fisiología moderna. Esto expresa el interés de René Descartes en la medicina, al punto que se habla de una medicina cartesiana $^{(36,38,39,40)}$. En el Discurso del método ${ }^{(41)}$, Descartes sostiene la esperanza de conseguir reglas que revolucionen la medicina y explicita la relación cuerpo-máquina:

Todo cuerpo es una máquina y las máquinas fabricadas por el artesano divino son las que están mejor hechas, sin que, por 
eso, dejen de ser máquinas. Si sólo se considera el cuerpo no hay ninguna diferencia de principio entre las máquinas fabricadas por hombres y los cuerpos vivos engendrados por Dios. La única diferencia es de perfeccionamiento y de complejidad. ${ }^{(41)}$

Con relación a la teoría de Harvey, René Descartes plantea al calor vital como la fuente de energía para el movimiento del corazón. Más allá de esa diferencia, adhiere a ideas que no hacen más que sostener la visión mecánica del cuerpo, construyendo su modelo teórico a partir de los principios de la física. Al cuerpo lo entiende como habitado por un alma racional que le da mayor complejidad, sin negar su creación divina. Así surge el dualismo cartesiano del espíritu y la materia, la mente y el cuerpo, al cual Descartes trata de sortear asignándole a la glándula pineal la función de interconectar lo corpóreo con lo incorpóreo $^{(27,30,33)}$.

¿Por qué se consolidó la teoría iatromecánica? Porque el lenguaje mecánico era en ese momento el paradigma dominante en occidente ${ }^{(42)}$, el único recurso disponible por la razón moderna para poder explicar la realidad, y por analogía el cuerpo humano. Negar lo mecánico era renunciar a lo científico, a lo objetivable, a lo hegemónico en ese momento histórico. Por eso los iatromecánicos extrapolaron los éxitos de la física al campo de la medicina $y$, al sustentarlos experimentalmente, desplazaron a los vitalistas, quienes despreciaron los intentos de cuantificación de la medicina y se resguardaron en lo cualitativo como patrón de cientificidad $^{(26)}$. Pero serán las inconsistencias de los iatromecánicos las que permitan que las teorías animistas compitan con sus explicaciones $^{(29,30,34)}$. La teoría mecánica también fue funcional al desarrollo de la fuerza de trabajo que necesitaba el desarrollo de un capitalismo incipiente ${ }^{(43)}$.

Georges Canguilhem señala que la relación entre organismo y máquinas ha sido estudiada en un sentido único, el funcionamiento del organismo a partir de la estructura de la máquina como algo dado, ocultando el sentido de dicha asimilación y la ausencia de problematización en la relación entre ciencia y técnica ${ }^{(44)}$. Para invalidar tales asimilaciones, Canguilhem destaca funciones del cuerpo humano inexistentes en la máquina como la polivalencia de los órganos, la vicariancia de funciones, y distintos fenómenos como la autoconstrucción, la autoconservación, la autoregulación y la autoreparación ${ }^{(44)}$; para lo cual respalda sus argumentos en Immanuel Kant, quien sostiene:

En una máquina, cada parte existe para la otra, pero no por la otra; ninguna pieza está producida por otra, ninguna pieza está producida por el todo, y ningún todo por otro todo de la misma especie. No hay un reloj que haga relojes. Ninguna parte se reemplaza por sí misma. Ningún todo reemplaza una parte de la que está privado. La máquina posee, pues, la fuerza motriz, pero no la energía formadora capaz de comunicarse a una materia exterior y propagarse. ${ }^{(44)}$

La máquina era la promesa de progreso (la ilusión), lo que haría posible el consumo ostentoso. Al cuerpo frágil debía ayudarlo la máquina, repararlo $y$, si fuera posible, reemplazarlo(45). Los cuerpos sanos debían estar destinados al trabajo, se había acabado el tiempo del ocio y del deseo. Era necesario hacer confluir lo económico-político con lo ideológico-cultural. Por todo esto, la moralidad victoriana, desde mediados del siglo XIX (con sus marcas de puritanismo), encierra la sexualidad en la familia, a la cual destina la función reproductora, y el sexo se limita a la reproducción y al cuarto de los padres, ya que los cuerpos deben estar a disposición del trabajo. Así, la hipocresía de la sociedad burguesa omite cualquier referencia a lo sexual y al deseo dentro de los parámetros de lo normal y lo científico. Esa moralidad (en realidad, una doble moral) coincide con el apogeo de la revolución industrial y el imperio británico ${ }^{(45)}$, que necesita el pensamiento del cuerpo como máquina, más allá de que la idea de organismo ya había superado el mecanicismo de Harvey y Descartes. 
La concepción mecánica le permitió al discurso médico expulsar el deseo, ya que el objeto de la medicina era la enfermedad y no la persona, que solo le interesó como sitio donde transcurren las distintas patologías, las cuales alcanzan estatus científico en la anatomía patológica. Se invierte así el orden, se parte de los cadáveres para conocer lo viviente, y se consigue hacer visible en el cadáver lo que era invisible en el ser viviente $^{(46)}$. René Leriche, cirujano francés afirmó: "si queremos definir la enfermedad tenemos que deshumanizarla"(46). Por ello, el discurso médico trata que el enfermo no hable, ni reciba mucho tiempo en la atención y, en general, solo será escuchado a partir del propio discurso médico ${ }^{(46)}$.

\section{La autopoiesis}

Si la teoría iatromecánica ha perdido estatus científico y ha sido superada por otros paradigmas, ¿por qué la idea del cuerpo como máquina tiene vigencia? Porque es la única manera de sostener la idea del enfermo como objeto, reproduciendo así la relación sujetoobjeto, central a la razón cartesiana (razón sustancial); expresión de una dualidad que se resiste a abandonar las universidades, y que se mantiene como ideología científica en los profesionales, expresándose en sus discursos, lo cual está en flagrante contradicción con los adelantos de la ciencia que utilizan, pero que no piensan ${ }^{(47,48)}$. También se debe reconocer que no pocos saberes y equipamientos de siglos anteriores mantienen su vigencia. La deontología médica oculta la ideología médica, y así los profesionales pueden desarrollar su tarea tranquilos entre "máquinas". En esa lógica, no hay espacio para el sujeto, ni individual, ni colectivo, como tampoco para la palabra y el vínculo ${ }^{(12,13,46)}$.

Las limitaciones del modelo de la máquina para explicar al cuerpo humano se hicieron notorias con el desarrollo de las ciencias. Así, la teoría general de sistemas incorporó el concepto de máquinas vivientes para superar el mecanicismo dominante. Para Ludwig von Bertalanfy, desde un criterio sistémico, los seres vivos eran sistemas abiertos procesadores de energía ${ }^{(49)}$.

Desde Chile, a partir de 1950, Humberto Maturana prefiere entender el cuerpo humano como una unidad autónoma, que crea fenómenos generales ${ }^{(50)}$. En su pasaje por el Instituto Tecnológico de Massachusetts había percibido sus diferencias con los investigadores que trabajaban en inteligencia artificial, quienes trataban de modelar los fenómenos biológicos, cuando para él, el ser vivo era una organización circular. Por ello, diferenció en el ser vivo el dominio de operar como totalidad en su espacio de interacciones, del dominio de operar de sus componentes, sin necesidad de hacer referencia a la totalidad que constituyen, es decir, el ser vivo como sistema vivo. De esas ideas, y junto a Francisco Varela, desarrolló los conceptos de sistemas autoreferidos u organización circular, que luego fueron reemplazados por el concepto de sistemas autopoiéticos ${ }^{(50)}$.

En la década de 1960, Humberto Maturana y Francisco Varela trabajaron sobre el origen y la organización de los seres vivos, diferenciándolos de las máquinas ${ }^{(50)}$. Los primeros manuscritos de su libro tuvieron muy mala recepción en los ámbitos científicos. Francisco Varela señala que el texto se consideró impublicable por editoriales de distintos países. También fue fría la recepción en las conferencias dictadas en las universidades de Boulder y Berkley. La primera reacción positiva provino de parte de Anthony Stafford Beer (renombrado cibernético y sistémico) que visitaba Chile en el marco del Ilamado Proyecto Cybersyn o Synco (Sistema de Información y Control) durante el gobierno de Salvador Allende. Anthony Stafford Beer fue quién finalmente escribió en 1972 el prefacio del libro ${ }^{(50)}$. Ivan Illich, que dio un apoyo importante para su edición, desde el centro $\mathrm{Cl}$ DOC, en Cuernavaca, al leer el texto afirmó "ustedes han logrado poner a la autonomía en el centro de la ciencia"(50). El libro fue publicado por la editorial de la Universidad de Chile en el año 1973, y recién se publicaría en inglés, en 1980, cuando las ideas ya habían trascendido y tenían reconocimiento a nivel internacional. En paralelo al libro, Maturana 
y Varela escribieron un artículo científico, rechazado por varias revistas y publicado recién a mediados de 1974 en Biosystems, que se constituyó en la primera referencia a la autopoiesis en lengua inglesa ${ }^{(50,51)}$. El fin de la experiencia socialista por la vía democrática obligó a los autores a exiliarse. No es fácil ni gratuito colocar temas en la agenda científica internacional desde el sur, sobre todo si se origina en un contexto donde el gobierno defiende intereses populares y se trabaja por fuera de los temas dominantes de la agenda científica internacional.

A partir de entonces, el concepto de autopoiesis se instala en el campo científico, en la biología y luego en la química. En 1991 es objeto de un editorial en Nature ${ }^{(52)}$. La autopoiesis, en tanto concepto, alcanzó un poder metonímico de gran alcance en las ciencias humanas. Francisco Varela entenderá que su uso no siempre fue fiel a los postulados originales ${ }^{(50)}$.

Con todo lo anterior, el ser vivo dejaba de ser un conjunto de moléculas para pasar a ser una dinámica molecular en un juego de relaciones e interacciones, una red cerrada de cambios y síntesis moleculares ${ }^{(50)}$. De allí la extrapolación que Francisco Varela haría años más tarde al campo de lo social, al plantear que "la cultura es un sistema autopoiético que existe en un espacio de conversaciones", idea que tiene fuerte influencia en Fernando Flores al sostener que una organización es una red de conversaciones ${ }^{(50,53)}$.

En síntesis, la autopoiesis evidencia que "el ser vivo es un ente sistémico, aun cuando su realización sea de carácter molecular", lo cual derrumba la idea de asociar el cuerpo humano, en tanto ser vivo, al de una máquina inerte y de negar que "el cuerpo está en lo social, porque lo social está en él cuerpo" ${ }^{\prime(6)}$. De estas formas de concebir lo vivo, podremos entender que la complejidad del proceso salud-enfermedad-atención (PSEA) sea ignorada por un "no saber en salud" producto de un no "pensar en salud"(48,54), que niega la complejidad biológica del cuerpo humano y el carácter sociohistórico del PSEA, habilitando la afirmación de Heidegger "la ciencia no piensa"(55). ¿Las consecuencias? La idea del cuerpo como máquina domina el sentido común de usuarios y profesionales (vida cotidiana, sujeto de la vida) ${ }^{(48)}$.

\section{El hospital como una construcción político-institucional}

Los primeros hospitales que se conocen siglos VI a.C.- remiten a los templos de Esculapio, a las legiones romanas y a las valetudinarias ${ }^{(56)}$. En la edad media, el hospital estuvo bajo la tutela de la iglesia, y se presentó como una manera de espacializar la pobreza y la marginación social bajo las formas de encierro y/o aislamiento. Así, fueron refugios para los enfermos y para quienes no tenían hogar, ni familia. Eran lugares para morir y, si al ingresar, la persona no estaba enferma, las malas condiciones de higiene no tardarían en enfermarla. Los hospitales eran instituciones de caridad dirigidas por eclesiásticos o dirigentes sociales de la comunidad ${ }^{(57,58)}$.

En el siglo XVIII, se inició el proceso de medicalización de la sociedad ${ }^{(59)}$. El hospital adquiere un rol terapéutico, dejó de ser una figura arquitectónica, para transformarse en otra tecnología más de cura ${ }^{(60)}$, por lo que debió ordenarse. Así, los hospitales marítimos comenzaron a incorporar nuevas formas organizativas, se instaló la cuarentena para evitar las epidemias y controlar el contrabando, que era parte del desorden que perjudicaba al comercio. Además, el hospital se jerarquizó socialmente, entre otras razones, por la profesionalización de los ejércitos. Esto implicó que la pérdida de un soldado resultara onerosa, por lo que, ante las heridas, debía ser cuidado y tratado. Es entonces que la cura de las personas aparece como necesidad y se crea, en Europa, la figura del médico del hospital con la implementación de la ronda médica, los registros sistemáticos de pacientes y los ateneos de discusión de casos. Así, tanto el individuo como la población se transforman en objeto del saber y la práctica médica, en el marco de una nueva experiencia que se desarrolla en el hospital(43,60).

A partir del siglo XVIII el hospital se transformó en un aparato de medicalización 
colectiva, la medicina rebasó los límites de los enfermos y de las enfermedades, y constituyó la biopolítica como forma de control sobre la población por parte de los gobiernos a través de la salud, la higiene, la natalidad, la longevidad y la raza. El poder se convirtió cada vez más en el derecho a intervenir para hacer vivir o dejar morir, en contraposición con lo que ocurría hasta entonces: el Estado tenía solo el derecho de dejar vivir y hacer morir ${ }^{(61,62,63)}$.

El hospital se fue transformando de una institución de pobres a una de ricos, y de estar financiada por la caridad a ser un buen negocio. La incorporación de la ciencia los transformó. Pasaron de "ciudadelas de ciencia y burocracia", a "ciudadelas de mercados" que tomaron la cura de la enfermedad como mercancía.

En el siglo XIX la bata blanca del médico reemplazó a la sotana negra del sacerdote. Así los médicos se transforman en los mecánicos de las máquinas y -secundariamenteen los sacerdotes de las almas ${ }^{(64)}$, sacerdocio que declinaría con el tiempo. Así, se pasa de instituciones mágico-religiosas a organizaciones basadas en clientelas privadas ${ }^{(45)}$, centradas en la atención de la enfermedad, y con cada vez menos atención hacia el cuidado de la personas.

\section{Del taller a la fábrica}

La conformación de los hospitales en EEUU se inició, en 1750, bajo dos formas: los voluntarios, manejados por laicos con un predominio de protestantes; y los públicos, dirigidos por comunas, condados o el gobierno federal. A partir de 1850 se dan diversas formas institucionales como las religiosas (inmigrantes católicos); étnicas, que servían de contención cultural frente a la discriminación y a los prejuicios; o especializadas en niños o mujeres. También los médicos homeópatas crean sus hospitales.

En las primeras décadas del siglo XX, el hospital, en general de propiedad privada, se constituyó en un actor central de la producción de la asistencia. Se incrementa su uso y comienza a desplazar a la medicina realizada en el consultorio, que era hasta ese momento el lugar preferencial de la atención médica $^{(1,43,64)}$.

La teoría iatromecánica, al instalar la imagen del cuerpo como máquina, habilitó la necesidad de un taller para repararlo, que pasó a ser la función del hospital desde el siglo XVIII, y allí radicó su hegemonía. Las ideas mecánicas subordinaron el hospital a la revolución industrial. Expresiones como "cada hospital es una industria procesadora de gente" ${ }^{\text {(58); }}$ "el organizado procedimiento de pacientes por médicos y máquinas, pareció similar a los métodos de la industria de producción en masa"(65); "taller de salud o industria médica (66); o "la transformación de la medicina en industria" expresan la penetración de las ideas maquínicas en el lenguaje ${ }^{(1)}$.

En la revolución industrial de los siglos $\mathrm{XV}$-XVI, los primeros talleres estaban localizados en las casas de los propietarios, allí tenían sus máquinas y herramientas. Pero a medida que las máquinas se complejizaron -aumentaron su tamaño y su valor económico- se produjo el traslado desde el domicilio a las fábricas. Lo mismo ocurrió, en EEUU, a fines del siglo XIX y principios del $X X$, cuando los médicos se trasladaron desde el domicilio al hospital. La diferencia con Europa fue que el médico siempre estuvo en el hospital; en cambio, en EEUU, el médico ingresó sin pacientes al hospital, y luego los trajo consigo ${ }^{(1)}$. Milton Roemer se refiere al "taller del médico" en alusión a aquellos profesionales del ámbito privado que, en EEUU, empiezan a utilizar el hospital como un consultorio y cobran allí sus honorarios a los pacientes. Esa práctica, iniciada a fines del siglo XIX, se generaliza a través de los médicos que vuelven de la primera guerra mundial y traen la experiencia positiva del trabajo cooperativo y en grupo $^{(56,65)}$.

A partir de 1873, la cofia de las enfermeras desplazó al velo de las religiosas, las que tradicionalmente se habían encargado de los pacientes. La profesionalización de la enfermería, basada en el modelo establecido por Florence Nightingale, deshace el papel ejercido por esas mujeres, dedicadas 
hasta entonces a la limpieza y consideradas sirvientas por los médicos. Starr señala que las nuevas enfermeras profesionales, con el tiempo se convierten en valiosas asistentes para los médicos, a pesar de que en sus inicios fueron resistidas por temor a que dejaran de obedecer sus órdenes. No fue diferente la suerte que tuvieron los trabajadores sociales al incorporarse al hospital ${ }^{(1,18,66,67)}$.

En 1890, surgen hospitales centrados en la rentabilidad económica, motivados por el desarrollo de la cirugía y las prácticas antisépticas iniciadas en 1880. La disminución de la mortalidad hospitalaria impacta positivamente sobre la imagen del hospital. La revolución bacteriológica, desencadenada por Pasteur en 1855, determina la creación del primer laboratorio bacteriológico en Filadelfia en 1896. Los adelantos científicos no solo favorecen el número de hospitales, sino que provocan una menor estadía de los pacientes en ellos, y la permanencia pasa a expresarse en días, en vez de semanas ${ }^{(1,66,67)}$.

Para liberarse del estigma de su fase precientífica, el hospital, en tanto institución, rechazó o aisló los casos contagiosos, los enfermos peligrosos o los casos incurables. Se trataba de generar una institución de salud que desplazara la imagen de lugar para la muerte. La compra de la tecnología para el desarrollo del hospital requería de capital, y los médicos buscaron ese financiamiento en los bancos, en los políticos y abogados, o conformaron fideicomisos. Se iniciaron también los comités de administración, que dieron lugar a la figura del administrador de hospitales ${ }^{(1)}$.

Con el tiempo, el médico basa su relación con el enfermo en tres hechos: la información que este le brindaba a través de la palabra, la observación del aspecto y sus características y, muy raramente, el examen físico. Este último, a lo sumo, se limitaba al sentido del tacto, o a tomar el pulso del paciente. El maletín negro, lugar del estetoscopio, la pañoleta, el bajalenguas, el termómetro, el alcohol, el estetoscopio y un martillo para los reflejos, conformaban toda la tecnología necesaria.

Los datos contenidos en la historia clínica eran asistemáticos y reflejaban únicamente el discurso médico. Los síntomas -lo que se podía referir-y los signos - lo que se podía objetivar- no siempre eran usados en ese sentido, sino que, por el contrario, muchas veces se los confundía. Esa separación comenzó con la incorporación de las primeras tecnologías (estetoscopio, microscopio, etc.), y alcanza su mayor expresión en la segunda mitad del siglo XX, cuando el desarrollo de sofisticados equipos acentúan este proceso, que desplaza al propio sujeto médico y construye la relación institución médica-enfermo ${ }^{(46)}$.

Entre el fin del siglo XIX e inicios del siglo XX, con el desarrollo de la medicina científica, los hospitales se jerarquizaron y comenzaron a ser una competencia para los médicos que ejercían de manera privada, quienes se sentían marginados de los adelantos científicos y de la posibilidad de ser parte de la institución hospitalaria. Solo un bajo porcentaje trabajaba en dichas organizaciones, de allí que se plantearan el control de esas instituciones, como también crear sus propios hospitales (microempresas), sobre todo, en los pueblos pequeños. Esos médicos temían que los hospitales de las grandes ciudades les quitaran a sus pacientes.

Desde las últimas décadas del siglo XIX, la profesión médica en EEUU resistió todo intento de regulación y/o participación, tanto estatal como privada. Para los primeros años del siglo XX, la American Medical Association (AMA) había conformado una posición de poder muy fuerte con influencia sobre la opinión pública y las agencias estatales. La AMA se apropió del campo de la atención médica, definiendo los contenidos, el financiamiento y su organización: "el poder público fue cedido a los profesionales" (68). Así los médicos lograron mantener la integridad de su oficio y el control de la división del trabajo, al contrario de lo que ocurrió con otros profesionales que, a pesar de la resistencia que ejercieron, fueron derrotados y vieron cómo su trabajo se transformaba en trabajo industrial.

La instrumentalización del conocimiento, que comienza en la segunda mitad del siglo XIX, va a confluir en la especialización médica. Hasta entonces, era mal visto que un médico se dedicara solo a una parte del 
cuerpo, la práctica era de carácter general. Por ello los médicos generalistas dominaban el campo y la especialización se asociaba a la charlatanería y a los curanderos. Pero ya en 1880, el número de publicaciones de los especialistas crecía a un ritmo mayor que el de los generalistas ${ }^{(65)}$. Hasta fines del siglo XIX, una parte reducida de la población consultaba al médico. Desde entonces hubo una fuerte presión para que se sancionaran leyes que otorguen licencias para ejercer la profesión, dado que el título se podía comprar, por ejemplo, en la Universidad de Michi$\operatorname{gan}^{(69)}$. El informe Flexner ${ }^{(22)}$ ordenó la situación a partir de 1910. Desde entonces, los médicos toman el monopolio de la cura, y el conocimiento pasa a centrarse en la ciencia, dejando atrás a la teología y a la filosofía ${ }^{(70)}$. En 1929, uno de cada cuatro médicos privados en EEUU era especialista a tiempo completo, relación que pasó en 1969 a tres de cada cuatro $^{(65)}$. A partir de la segunda década del siglo XX, el conocimiento médico aseguró una calidad de cura tal, que un paciente enfermo eligiendo un médico al azar tenía una probabilidad mayor al $50 \%$ de favorecerse del encuentro ${ }^{(71)}$.

Entre 1911 y 1921, el número de pacientes en New York que pagaba por su internación subió del $18 \%$ al $45 \%$ y, el de los pacientes privados, del $20 \%$ al $24 \%$. Las desigualdades en la internación eran notorias, los pacientes del hospital eran internados en salas comunes, en cambio los internados por médicos privados tenían habitaciones individuales, y mayores posibilidades de recibir visitas.

Durante la década de 1930, las condiciones económicas derivadas de la "Gran Depresión" forzaron la creación de nuevos sistemas de financiación, como las compañías de seguros médicos organizadas por los propios profesionales, como Blue Cross. Esto no solo reflejaba la especialización de la profesión médica, sino que produciría un incremento del número de hospitales, impulsado por los seguros de salud privados que contribuyeron a su crecimiento y a la centralidad que adquieren en el sistema de salud hasta mediados de $1970^{(72)}$.
Los médicos decidieron valerse de los hospitales y no ser sus empleados, pretendían mantener la autonomía sin perder el control. Expresión de esto es que en el año 1937, radiólogos y anestesistas consiguen que los hospitales no les paguen salarios sino honorarios ${ }^{(1)}$. El desarrollo tecnológico trajo nuevos escenarios: ¿quién controlaría y quién se apropiaría de la renta de las nuevas tecnologías que se incorporaban? Para la década de 1920, las enfermeras dominaban el campo de la anestesia y el manejo de los equipos de rayos $X$. Todo se revirtió en las siguientes décadas, cuando los médicos lograron el control total de las especialidades $y$, por lo tanto, de su rentabilidad, subordinando a la enfermería ${ }^{(1)}$.

Entre las décadas de 1940 y 1960, la AMA conforma "el triángulo de acero" al contar con el apoyo de otras organizaciones médicas, las agencias de seguros y el empresariado. Todas ellas tenían en común fuertes intereses privados y un congreso sensible a sus peticiones. En conjunto se oponían a las reformas de la atención médica, a las que calificaban como "el paso final e irrevocable hacia el socialismo de Estado", que Ilevaría a los médicos "a la esclavitud"(68), los seguros privados de salud constituían su principal propuesta.

El interés de los médicos estaba en la atención del proceso agudo. Fuera de él, el paciente perdía interés, ya no había nada que hacer, así se daban altas sin considerar la recuperación del paciente, ni su rehabilitación. Se comenzaba a observar cómo la actividad recaía más en los profesionales que en los administradores. Lo cual dio inicio al dominio total de los hospitales por parte de los médicos $^{(1,73)}$. El financiamiento de los hospitales era un problema, a la vez que resultaba evidente que eran los médicos la principal variable para explicar la internación de los pacientes $^{(74)}$. Ellos aportaban los pacientes que pagaban al hospital, y comienzan a superar la importancia económica que hasta entonces tenían los fideicomisos ${ }^{(1)}$.

En los hospitales, los médicos podían observar la evolución de las enfermedades individuales y sus diagnósticos en una escala 
mucho mayor que en su práctica privada. Las disecciones post mortem en reclusos proporcionaron más información sobre las patologías. Los hospitales se convirtieron en centros de investigación (sobre todo, después de la Segunda Guerra Mundial). Los esfuerzos para mejorar los usos de los medicamentos implicaron ensayos clínicos y análisis estadísticos. El nacimiento y la muerte pasaron del hogar al hospital. La autoridad moral del médico, que hasta entonces se basaba en cualidades personales, pasó a sustentarse en las competencias científicas. La experimentación clínica se hizo desenfrenada, a veces abusiva, con poca protección para los pacientes $^{(1,57)}$. Se consolidaba así, una cultura hospitalocéntrica que naturalizaba afirmaciones como: "sin hospitales es imposible llevar los beneficios de las ciencias de la salud a la gente ni lograr estándares de salud nacional"(75).

Lo relatado a lo largo del texto, centrado en EEUU, se observa con matices en la mayoría de los países. Valga la siguiente cita de un sanitarista chileno sobre el Sistema Nacional de Salud (iniciado en Chile en 1952), que demuestra que la propiedad pública tampoco resuelve las limitaciones de la cultura hospitalocéntrica en la atención y cuidado de las personas:

\section{Para la organización chilena, el hospital es el eje fundamental de la organización médica. Está tan lejos de ser el último eslabón que nuestra clase proletaria no dice "voy a consultar al médico" sino que siempre habla "voy al hospital". La tradición lo obliga a ello y en su lenguaje habitual no hace más que denunciar nuestro defecto de organización. ${ }^{(76)}$}

Si bien estas palabras son de fines de la década de 1960, resulta necesario interrogarnos acerca de los motivos por los cuales continúa siendo dominante centrar las políticas de salud en los hospitales y no en los territorios y los centros de salud. ¿Qué evidencias científicas hay para ello?

\section{De la fábrica a la empresa}

Las formas organizativas de los hospitales del siglo XX recibieron influencias de la teoría general de la administración. Se pretendía que el hospital funcione de manera articulada como lo hacía la fábrica ${ }^{(77,78)}$, pero el financiamiento resultó siempre un problema, a tal punto que llevó a considerar si la atención médica era una inversión social, o debía ser considerada un gasto, dudando incluso sobre si ese gasto guardaba relación con los resultados en salud ${ }^{(1,79)}$. La metáfora que utiliza Paul Starr para graficar la situación es: "la medicina norteamericana pareció dar el salto de la escasez tenaz al exceso irrefrenable, sin haber conocido en ningún momento una suficiencia feliz", era necesario "frenar el apetito aparentemente insaciable de recursos" de esa forma de ejercer la medicina ${ }^{(1)}$.

El tema de los costos y los gastos no era nuevo. Entre 1925 y 1926 se realizaron dos conferencias sobre los factores económicos que influían en la organización de la medicina. En esos encuentros se definió la creación del Committee on the Cost of Medical Care [Comité de Costos de la Asistencia Médica] para controlar los gastos, que luego de 5 años de investigaciones, en 1932, publicó 28 volúmenes con el título Medical Care for the American People [Atención Médica para el pueblo Americano] ${ }^{(1)}$. Entre 1950 y 1960, los costos de la atención hospitalaria crecieron de manera incesante en EEUU, los gastos en hospitales de comunidad aumentaron a un promedio del $8 \%$ anual $y$, en 1965, a un promedio del $14 \%$ anual. Al analizar los costos se detectaron cirugías innecesarias y pacientes que no necesitaban estar internados. Los médicos habían entrado en un juego -que continua en la actualidad-que era fomentado por el pago de prestaciones, de manera que, a mayores costos, recibían mayores reembolsos. De este modo, la figura del tercer pagador aparecía en escena, lo cual favorecía el cumplimiento de la Ley de Roemer, que señala que el número de camas disponibles crea la demanda de su uso ${ }^{(1)}$. El gasto en salud y su financiamiento se transformaron en un tema central, al punto de que 
si comparamos el gasto como porcentaje del PBI, entre los años 1960 y 2017, crece más del triple; en tanto el gasto por internación se multiplica por 12 , a pesar de caer la tasa de internación, y el gasto hospitalario por 200, pese a que el número de hospitales se reduce un $20 \%$ y la población total de EEUU aumenta un $75 \%$ (Tabla 1) ${ }^{(24,80,81,82,83)}$.

A la par del aumento del gasto se produce una concentración de la tecnología y, por ende, de las internaciones en menos hospitales, dando inicio a una ambulatorización de la asistencia médica, no necesariamente centrada en el viejo consultorio privado, sino en microempresas ${ }^{(84)}$. En esa transición confluyen la práctica quirúrgica ambulatorial, la eficacia terapéutica de drogas que prescinden de la internación, el avance en ciertas tecnologías (diálisis peritoneal) y la creación de instituciones para ancianos. A pesar de ello, no se eliminaron dos grandes problemas: el aumento de los costos y las sobreprestaciones. Todo ello no ocurría solo en los EEUU: la crisis de financiamiento de los sistemas de salud era, y continúa siendo, un problema a nivel mundial(24).

A partir de la década de 1970 , se inicia la pérdida de la legitimidad del poder profesional médico en EEUU; se da "fin a un mandato", afirma Paul Starr ${ }^{(1)}$. En dicho fenómeno confluyen dos factores: la merma de confianza en la capacidad de la ciencia y la tecnología para promover el bienestar de las sociedades; y la incapacidad de la medicina para hacerse cargo en forma integral de la problemática de salud. En paralelo surgen los movimientos por los derechos a la salud y los derechos del paciente, y el movimiento de las mujeres que desconfían de los profesionales y de las instituciones bajo su responsabilidad. El tema del lugar, del modo y el tipo de asistencia en el parto, es uno de los más discutidos. Se busca desmedicalizar y desinstitucionalizar, tratando de limitar la

Tabla 1. Indicadores hospitalarios, gasto en salud como porcentaje del PBI y población total. EEUU, 1873-2017.

\begin{tabular}{|c|c|c|c|c|c|c|c|c|c|c|c|c|c|}
\hline \multirow[t]{2}{*}{ Años } & \multirow[t]{2}{*}{$\mathrm{NH}$} & \multicolumn{3}{|c|}{$\begin{array}{l}\text { Número de camas } \\
\text { en millones }\end{array}$} & \multirow[t]{2}{*}{$\mathrm{NI}$} & \multicolumn{2}{|c|}{$\begin{array}{c}\text { Tasa de } \\
\text { ocupación }\end{array}$} & \multirow[t]{2}{*}{ PDE } & \multirow[t]{2}{*}{ GIHC } & \multirow[t]{2}{*}{$\mathrm{GH}$} & \multirow[t]{2}{*}{ TNH } & \multirow[t]{2}{*}{ GSPPBI } & \multirow[t]{2}{*}{ PT } \\
\hline & & Total & $\mathrm{F}$ & $\mathrm{NF}$ & & $\mathrm{F}$ & $\mathrm{NF}$ & & & & & & \\
\hline 1873 & $<200$ & - & - & - & - & - & - & - & - & - & - & - & 39 \\
\hline 1875 & 661 & - & - & - & - & - & - & - & - & - & - & - & 39 \\
\hline 1909 & 4.000 & - & - & - & - & - & - & - & - & - & - & - & 92 \\
\hline 1928-1930 & 7.000 & - & - & - & - & - & - & - & - & - & - & - & 122 \\
\hline 1950 & 6.788 & 1,45 & - & - & 18,48 & - & - & - & - & 2,1 & - & - & 150 \\
\hline 1960 & 6.876 & 1,65 & - & - & 25,03 & - & - & - & - & 5,6 & - & 5,0 & 179 \\
\hline 1973-1975 & 7.156 & 1,46 & 0,131 & 1,333 & 36,16 & 76,7 & - & 11,4 & $1.030,34$ & 27,2 & 3.537 & 7,2 & 211 \\
\hline 1980 & 6.965 & 1,36 & 0,117 & 1,247 & 38,89 & 80,1 & 77,4 & 10,0 & $1.851,04$ & 100,5 & 3.500 & 9,4 & 227 \\
\hline 1990 & 6.649 & 1,21 & 0,098 & 1,115 & 33,77 & 72,9 & 69,2 & 9,1 & $4.946,68$ & 250,4 & 4.046 & 12,2 & 250 \\
\hline 2000 & 5.810 & 0,98 & 0,053 & 0,930 & 34,89 & 68,2 & 65,9 & 5,8 & $6.648,62$ & 415,5 & 3.940 & 12,5 & 282 \\
\hline 2010 & 5.754 & 0,94 & 0,044 & 0,897 & 36,91 & 65,3 & 66,6 & 5,4 & $10.313,44$ & 822,3 & 3.871 & 16,4 & 310 \\
\hline 2016-2017 & 5.534 & 0,89 & 0,030 & 0,860 & 35,16 & 64,7 & - & 6,1 & $12.777,25$ & $1.082,5$ & 3.761 & 17,0 & 316 \\
\hline \multicolumn{14}{|c|}{$\begin{array}{l}\text { Fuente: Elaboración propia con base en Starr }{ }^{(1)} \text {, Reiser }{ }^{(65)} \text {, Banco Mundial }{ }^{(24)} \text {, Catlin y } \text { Cowan }^{(80)} \text {, Hartman et al. }{ }^{(81)} \text {, Diez Roux y Spinelli(82), Organización } \\
\text { Panamericana de la Salud }{ }^{(83)} \text {, Health Forum }{ }^{(85)} \text {, Statita }{ }^{(86)} \text {, National Center for Health Statistics }{ }^{(87)} \text {. }\end{array}$} \\
\hline \multicolumn{14}{|c|}{$\begin{array}{l}\mathrm{NH}=\text { Número de hospitales; } \mathrm{F}=\text { Federales; } \mathrm{NF}=\text { No federales; } \mathrm{NI}=\text { Número de internados (en millones); PDE = Promedio de días de estada; GIHC = Gasto por } \\
\text { internación en hospitales comunitarios (en dólares por paciente); GH = Gasto hospitalario (en billones de dólares); TNH = Total de nacimientos hospitalarios (en } \\
\text { millones); GSPPBI = Gasto en salud como porcentaje del producto bruto interno; PT = Población total (en millones). }\end{array}$} \\
\hline
\end{tabular}


autonomía y el poder de los profesionales ${ }^{(1)}$. Por esos mismos años Ivan Illich escribe: "la empresa médica se ha vuelto un peligro mayor para la salud"(31).

En 1970, la revista Fortune publicó un artículo que mencionaba: "Los médicos crearon el sistema, lo manejan, y son el obstáculo más formidable que impide su mejoramiento"(1). Una afirmación así, en una revista económica, era imposible hasta entonces. Los intereses de los gobiernos, las empresas y los movimientos liberales de protesta, que pugnaban por una atención médica igualitaria, coincidían en denunciar la crisis de la atención y responsabilizaban de ella a los médicos. Se instala la idea de que las decisiones no podían seguir en manos de los médicos, debían ser políticas, y la atención médica debía comenzar a alejarse de los hospitales y buscar sistemas más eficientes, además de regular las tarifas de esas instituciones. Así fue que las ideas y propuestas de reformas comenzaron a ser parte de la agenda política.

La reforma de la atención médica fue tratada tanto por demócratas como por republicanos. Todo el proceso fue calificado desde la AMA como "la intromisión más peligrosa del gobierno en la práctica médica en la historia de la Nación"(1). A fines de 1969, se propuso un seguro nacional de salud auspiciado por Nelson Rockefeller; en 1970, Edward Kennedy y Martha Griffiths proponen un plan de Seguridad de la Salud; y en 1971, Richard Nixon anuncia "una nueva estrategia nacional de salud" donde las Health Maintenance Organization (HMO) serían la principal innovación; las que recién cobran fuerza en 1976 bajo el gobierno de Carter ${ }^{(1)}$. Las HMO fueron definidas como "un sistema organizado de prestación de servicios para la salud, que aportaba una vasta gama de servicios de atención a una población voluntariamente inscripta, a cambio de un pago fijo y periódico"(58).

Entre 1970 y 1974, la organización médica comienza a deslizarse fuera del control profesional hacia complejos de escuelas médicas y hospitales, agencias reguladoras, empresas de seguro, conglomerados, holdings y otras empresas; y desde los profesionales de la medicina hacia economistas y expertos en administración ${ }^{(1,79)}$. Ese "fin del mandato médico" señala el inicio de la separación entre la medicina y los médicos, quienes quedan en una encrucijada entre los nuevos escenarios (la medicina como parte del mundo de los negocios) y un ejercicio profesional que había resistido hasta entonces los embates del capitalismo por regularlo y que pretendía continuar con sus viejas prácticas. Lo anterior no hacía más que expresar el fin de un ciclo de expansión de producción, con una mayor integración y control sobre los prestadores de servicios ${ }^{(88)}$. Era el momento de las grandes corporaciones transnacionales, generadoras de valores e identidades que se desterritorializaban, afectando a los Estados-nación y a sus culturas. Estas corporaciones, a la vez que condicionaban los procesos decisorios de los Estados, pretendían mantenerse autónomas frente a ellos y a la sociedad civil; lo cual demostraba que consideraban a sus propietarios como los únicos sujetos de derechos ${ }^{(89)}$.

A fines del siglo $X X$, la atención hospitalaria se transformó en una industria gigantesca cooptada por la ideología del mercado. Se pasó de relaciones comunales -al punto que, a mediados del siglo XX, los directivos podían llegar a tener sus casas en los mismos terrenos que el hospital-, a relaciones asociativas de intercambio y/o asociaciones económicas $^{(1)}$. En las últimas décadas de fines del siglo XX, el hospital se convirtió en un actor del complejo médico industrial, relacionado a intereses privados y al capital financiero, como parte del proceso de industrialización de la medicina.

Además, en tanto institución, se volvió un enigma para muchas disciplinas: se lo analizó como sistema social, como organización compleja ${ }^{(90,91)}$ o como pequeñas sociedades; $y$, mientras desde la sociología se preguntaban ¿por qué se aleja de los modelos burocráticos?, desde la economía el interrogante era ¿qué es lo que lo maximiza?, ya que la rentabilidad no lo era ${ }^{(1,92)}$. 


\section{EL COMPLEJO MÉDICO INDUSTRIAL: DE HIPÓCRATES A ADAM SMITH}

El 17 de enero de 1961 el presidente de EEUU, Dwigth Eisenhower, en su último discurso al país, advirtió sobre una enorme industria armamentística, a la que llamó "el complejo militar-industrial"; el cual, junto con un inmenso establishment militar había adquirido gran poder político y económico. Su preocupación radicaba en el posible conflicto entre intereses públicos y privados en la investigación y desarrollo tecnológico, en un área crucial como la defensa nacional ${ }^{(93)}$.

En enero de 1970, la revista Fortune publicó un número con el título "Our alling medical system", dedicado al crecimiento tecnológico en la medicina, y al poderío económico del sistema de salud de EEUU. Los títulos de las notas eran: "It's time to operate"; "Better care at less cost without miracles"; "Change begins in the doctor's office"; "Hospitals need management even more than money". Una nota de ese número fue escrita por Harold Meyers bajo el título "The medical industrial complex", en la que describió cómo el desarrollo tecnológico para el diagnóstico, tratamiento y la cura de enfermedades llevó a descubrimientos e innovaciones como la aparición de corazones artificiales, válvulas cardíacas artificiales, elementos de microcirugía, marcapasos, máquinas de cobalto, camas especiales para hospitales, máquinas para dializar, cromatógrafos, análisis automáticos de pruebas sanguíneas y el desarrollo de la electrónica aplicada al campo de la medicina, entre otros ${ }^{(94)}$.

Ese desarrollo tecnológico atrajo nuevas empresas, que se sumaron a las ya existentes, para transformar la atención médica en un objeto más dócil al mercado. El negocio de la fabricación y venta de los productos que utilizaban profesionales y hospitales produjo una unión de compañías -y/o aperturas de divisiones médicas al interior de otras-, para intervenir en un mercado de 63 billones de dólares (año 1969), del cual una buena parte era para esas manufacturas. Ese mercado venía creciendo a un ritmo de entre un $10 \%$ y un $15 \%$ anual, al punto de que se hablaba de un "dólar salud". Bisturís, material para sutura, guantes, jeringas, jaulas para animales de laboratorio, máquinas para conservar órganos, incrementaron las ganancias de empresas ya existentes como Eli Lilly, Baxter Laboratories, Johnson \& Johnson y General Electric; y propiciaron la incorporación de nuevas compañías como American Hospital Supply Corp, Philip Morris, Zenith, Motorola, Adressograph Multigraph, Bigelow-Sanford, Lockheed; Monsanto, International Paper, Scott Paper y Kimberly Clarck.

En 1975, Ivan Illich afirmó en Némesis médica ${ }^{(31)}$ : "La medicina institucionalizada es una grave amenaza para la salud. El impacto del control profesional sobre la medicina, inhabilita a la gente, y ha alcanzado las proporciones de una epidemia". También describió "la enfermedad del progreso médico", y señaló la iatrogenia como su consecuencia. En la mitología griega, Némesis personifica la justicia divina y la venganza de los dioses, la cual caía sobre "los mortales que usurpaban los privilegios, que los dioses guardaban para sí mismos", en el intento de ser héroes en lugar de ser humanos. De allí el título del libro de Iván Illich que tomó mayor sentido y significado con el tiempo ${ }^{(31,95)}$. Las sociedades médicas se horrorizaron del texto, que fue también criticado por Juan Cesar García(96) -fundador de la Medicina Social Latinoamericana- por su carácter fenomenológico; crítica que Pasos Nogueira reconsideró tres décadas después ${ }^{(97)}$.

Entre 1970 y 1980 se terminó por construir "un nuevo amo", el complejo médico industrial, que transformó la estructura institucional del campo de la salud, desplazando el poder desde la AMA hacia el capital financiero $^{(1)}$. El inicio de ese proceso se relaciona con la aprobación, en 1965, del Medicare y Medicaid que hicieron que la atención médica sea muy lucrativa, dado el financiamiento público, por lo que atrajo a los inversores ${ }^{(1)}$. Esto termina por reformular los vínculos entre médicos, hospitales, escuelas de medicina, empresas de seguros, industria farmacéutica, industria de tecnologías médicas y otros negocios lucrativos ligados al campo de la salud ${ }^{(1)}$. 
En 1980, diez años después de la primera mención al complejo médico industrial en el número de Fortune ya citado, Arnold Relman editor en jefe del New England Journal of Medicine hace referencia en un artículo de dicha revista, al "nuevo complejo médicoindustrial". Allí, analiza la aparición de una red de corporaciones privadas implicadas en el negocio de la salud con una finalidad meramente lucrativa, que surge en la década de 1970 en EEUU ${ }^{(25)}$. Se calculaba que en ese país, el complejo médico industrial tenía un ingreso entre los 35 y 40 mil millones de dólares anuales (casi la cuarta parte de los gastos totales de asistencia médica durante 1979), y que las ganancias de esas corporaciones se habían elevado entre un $30 \%$ a un $35 \%$ en $1979^{(25)}$. Frente a esto, Relman se pregunta ¿podemos dejar la atención médica librada al juego del mercado, cuando se carece de estudios suficientes sobre sus aportes a la calidad y/o la disminución de costos? ${ }^{(25)}$. En ese momento, EEUU tenía un gasto en salud del $10 \%$ del PBI, y Relman afirmaba que "de ningún modo los costos pueden continuar su escalada al ritmo presente a menos que se sacrifiquen otros objetivos sociales"(25). En la actualidad, 38 años después de esa afirmación, EEUU tiene un gasto en salud equivalente al $17 \%$ de su PBI, y casi un $15 \%$ de su población (unos 45 millones de habitantes) carece de atención médica.

Arnold Relman incluye en el complejo médico industrial, no solo a la industria farmacéutica, que venía siendo motivo de críticas y denuncias desde la década de $1970^{(98)}$, sino también a la producción de tecnologías médicas y a otras instituciones sanitarias, profesionales y agentes relacionados, que conformaban un gran emporio económico con una influencia decisiva en aspectos transcendentales como la investigación, la formación y la asistencia médica. Arnold Relman señala que el complejo médico industrial es una red creciente de corporaciones dedicada a suministrar servicios de salud -geriatría, hemodiálisis, cuidados domiciliarios y estudios diagnósticos de laboratorio- con fines lucrativos. Prestaciones que, hasta entonces, eran proporcionadas por instituciones sin fines de lucro, profesionales de manera individual o formaban parte de prácticas culturales de los grupos familiares ${ }^{(25)}$. El concepto de complejo médico industrial pasa a ser denominado, posteriormente, como complejo médico-industrial-financiero o complejo médico-financiero ${ }^{(99,100,101,102,103)}$.

Arnold Relman resalta la naturalización de la atención médica como un producto del mercado, lo cual despierta el interés de Wall Street, que se concentró en esa enorme industria médica privada que crecía rápidamente, con un futuro económico brillante y relativamente invulnerable a la recesión. Por eso Arnold Relman plantea la necesidad de su regulación, a la vez que duda de los médicos en esa función, dado los conflictos de intereses en sus prescripciones e intervenciones. Según sus propias investigaciones "era probable que más del $70 \%$ del gasto total para la atención médica sea el resultado de decisiones emitidas por médicos"(25), lo que evidencia que el único riesgo importante para los inversores es la amenaza de un mayor control gubernamental ${ }^{(25)}$. Se plantea así un dilema entre "intereses económicos y valores sociales"(103). Las preocupaciones de Arnold Relman se confirman en publicaciones posteriores que señalan cómo el interés económico desplaza la preocupación por la salud, y cómo la producción de conocimientos se realiza transformando a los individuos y/o poblaciones en objetos a través de ensayos clínicos, que se utilizan luego como evidencias científicas ${ }^{(104,105,106,107,108)}$.

La organización del complejo médico industrial sienta las bases para niveles elevados de "control integrado" que se caracterizan por el cambio del tipo de propiedad y de control (las empresas lucrativas reemplazan a los organismos públicos y de beneficencia); la integración horizontal (dominio de sistemas multiinstitucionales y cambio de control de las comunidades a espacios regionales, nacionales y/o internacionales); la diversificación y reestructuración corporativa (conglomerados de compañías que participan en numerosos mercados); la integración vertical (organizaciones que abarcan distintos niveles y fases de la atención médica); la concentración de la industria (mayor control 
y propiedad sobre los servicios en mercados cada vez mayores) $)^{(1)}$.

El complejo médico industrial induce una atención médica muy onerosa, basada en modelos de negocios y no en resultados científicos validados ${ }^{(109)}$. Al respecto podemos recuperar distintas citas que señalan cómo las publicaciones de ensayos clínicos que demuestran efectos "negativos" toman de dos a cuatro años más en publicarse que las que señalan efectos positivos, periodo durante el cual los pacientes pueden recibir tratamientos ineficaces o dañinos ${ }^{(109,110)}$. Todo lo anterior es posible por las relaciones entre profesionales e industria, evidencia de la existencia de una "ciencia de la industria" con fuertes vínculos interprofesionales centrados en prácticas de comercialización y modelos financieros y productivos, cuya preocupación no es la salud de las personas ${ }^{(109)}$. El poder del complejo médico industrial se expresa en las capacidades para medicalizar situaciones sociales y/o naturales, como el de definir nuevas enfermedades ${ }^{(111)}$.

El aumento de la medicalización en la sociedad es producto de cambios que expresan la expansión diagnóstica de enfermedades, las mejoras biomédicas y el envejecimiento poblacional. Todos estos hechos afectan a más y nuevas poblaciones, y conducen a la creación de más y nuevos mercados. Como consecuencia de lo anterior se observa cómo las personas en la vida cotidiana asumen como problemas médicos la andropausia, la calvicie o el déficit de atención/hiperactividad en niños, que se expandió hasta incluir a los adultos ${ }^{(112)}$. La medicalización avanza también sobre el padecimiento mental, el alcoholismo, las adicciones, el parto y la expansión de cirugías estéticas (implantes mamarios, lifting, etc.). Otra expresión de esa medicalización es el aumento del número de diagnósticos en el DSM-IV, que pasa de 106 en 1952, a 297 en $1994^{(112,113)}$, lo que expresa cómo se amplían los criterios de "anormalidad", y del control social por parte del conocimiento médico ${ }^{(112)}$, lo cual confronta con la afirmación de Georges Canguilhem en 1943: "existe una medicina porque hay hombres que se sienten enfermos, y no porque hay médicos se enteran por ellos los hombres de sus enfermedades"(8).

Las relaciones financieras entre el complejo médico industrial y los profesionales de la medicina se encuentran en la investigación (ensayos clínicos), en la educación (grado y posgrado) y en la educación médica continua, dejando a la luz los conflictos de intereses existentes ${ }^{(114,115,116)}$, dado que la decisión del médico está influenciada por la rentabilidad económica de la industria. Esa relación produce un sesgo en las decisiones, efecto que se multiplica, si el que genera "la influencia" es un educador en su especialidad, dada su posición de liderazgo ${ }^{(114,115)}$.

Hay claras evidencias de que el patrocinio de la industria en el campo de la salud, en general, siempre resulta en un balance económico a su favor ${ }^{(117)}$. Se ha estimado que por cada dólar que gasta la industria en los médicos obtiene $\$ 3,56$ dólares de ganancia ${ }^{(116)}$. No menor es el hecho de que un tercio de los ingresos operativos de muchas de las grandes sociedades médicas de EEUU dependan del complejo médico industrial ${ }^{(115)}$. La aceptación de consultorías, honorarios, regalos, gastos de viajes y cenas por parte de los profesionales son algunas de las formas con las que los fabricantes de equipos y la industria farmacéutica "seducen" las conductas prescriptivas de los profesionales ${ }^{(114,115,116,118)}$.

Así, mientras algunos postulan la regulación del complejo médico industrial ${ }^{(119)}$, otros defienden su libertad, alegando el fantasma de la mediocridad científica que produciría la regulación del Big Pharma ${ }^{(120)}$. No hay dudas de que el conocimiento médico debe mucho a la investigación, en general, iniciada en laboratorios de universidades muchas de ellas públicas- y luego llevada a gran escala por la industria. Los intereses económicos que se mueven detrás de aparentes discusiones científicas son muy poderosos, lo que puede apreciarse en el libro La verdad sobre la industria farmacéutica ${ }^{(104)}$ de Marcia Angell (editora responsable del New England of Medicine entre 1999-2000, la primer mujer en serlo). 
En el año 2014, Peter Gøtzsche, médico danés, director del Nordic Cochrane Center, publicó un libro que en su título relaciona a la industria de los medicamentos con el crimen organizado ${ }^{(121)}$. Esa publicación recibió el premio al mejor libro del año por parte de la British Medical Association. A lo largo de sus 504 páginas desmenuza la relación de la industria farmacéutica con distintos temas como asma, epilepsia, diabetes, ensayos clínicos, conflictos de intereses en las publicaciones científicas, ausencia de regulación por parte de los Estados y el uso indiscriminado de antipsicóticos y su relación con el suicidio en niños; y expresa cómo el negocio de los medicamentos se hace a expensas de la salud de las personas. En el año 2018, Cochrane Colaboration aparta de su cargo a Gøtzsche, quien denunció a esa institución por la creciente falta de colaboración democrática y pluralismo científico ${ }^{(122)}$.

En el año 2012, al responder cómo había resultado su predicción sobre el complejo médico industrial, Arnold Relman dijo que su especulación se había vuelto aún peor de lo que él podría haber imaginado ${ }^{(123)}$. Ante la dinámica propia del campo de la salud y su falta de regulación, Susana Belmartino se preguntaba ¿quién será el árbitro? ${ }^{(124)}$.

\section{DE ROBOTS, PROFESIONES Y ARTE-SANOS}

En el siglo XX, la discusión sobre la práctica médica osciló entre dos posiciones: una dominante que profundizaba lo instrumental (reduciendo a los profesionales a la condición de técnicos), teniendo como meta la robotización de los procesos de trabajo; y otra, que se volvió subalterna, basada en las prácticas del viejo médico general que resaltaba la importancia de las relaciones personales y el vínculo entre trabajadores y usuarios, tratando de recuperar el trabajo médico por fuera de lo corporativo ${ }^{(12,84,125,126)}$. En ese devenir, la ciencia se volvió sinónimo de tecnología y se deshumanizó (Cuadro 1).

Las diferencias planteadas nos hablan de una tendencia que busca reemplazar el trabajo artesanal por el homo faber, pero que indudablemente no logra transferir la pasión y el poder heurístico de lo artesanal a lo técnico. La idea del trabajo médico con componentes artesanales se encuentra en la tesis de libre docencia de Maria Cecília Donnangelo, presentada en 1975, en la cual, desde un abordaje más estructural, señala la tensión de esa transición ${ }^{(43)}$.

Cuadro 1. Diferencias entre el trabajo que realizaban los médicos alrededor de 1900 y el que realizan en la actualidad.

Médicos que trabajan en pequeña escala, remunerados con honorarios (1900)

Autonomía respecto de los términos y el contenido de trabajo

Trabajo más generalizado y controlado por el mismo médico

Objeto del trabajo

Herramientas de trabajo

El médico acostumbraba a considerar a quienes lo consultaran como "sus pacientes"
Médicos que trabajan en organizaciones burocráticas

Trabajo típicamente segmentado y dirigido por administradores de acuerdo con las imposiciones organizacionales (lucro) y reglamentaciones gubernamentales.

Técnicamente los pacientes son clientes o miembros de la organización, y los médicos los comparten con otros especialistas

Por lo general, el médico era su dueño o los alquilaba, y también se ocupaba de contratar a sus empleados
Por lo general, los medios tecnológicos pertenecen a la organización empleadora y son operados por otros empleados burocráticos. 
La idea de la máquina llevó a pensar que la repetición implicaba aprendizaje (máquinas replicantes como el marcapaso), sin preocuparse por el aburrimiento que esto representa. Por el contrario, la destreza manual compleja no representa aburrimiento, lo cual evidencia que solo cuando la cabeza y las manos se separan se afecta el interés y la motivación del trabajador, ya que el trabajo pierde su singularidad ${ }^{(128)}$. La regla de Isaac Stern -para la música- señala que cuando mayor es la destreza, más tiempo se puede dedicar al ensayo sin aburrirse. Esa regla es extrapolable a cualquier trabajo de carácter

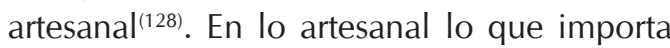
es la calidad, la cual se relaciona a la destreza del maestro, y no a los instrumentos. El capital aniquiló el trabajo artesanal y se propuso construir técnicos ${ }^{(129)}$. En la Grecia clásica, la techné (ocupación profesional lucrativa), se oponía a la paideia (saber desinteresado) (130), como también la techné, en su acepción de fabricar, se diferenciaba de la poiesis, en tanto creación. Para Platón, la poiesis permitía el paso del no ser al ser, era un hacer creador $^{(130)}$. Heidegger afirma que la esencia de la técnica no es la técnica, y que se debe diferenciar entre la antigua técnica artesanal y la técnica moderna, la cual es imposición, a diferencia de la técnica artesanal que no se imponía sobre los entes, sino que los respetaba. Para Heidegger, "la esencia de la técnica es ambigua en un sentido elevado", ya que combina el peligro con la solución ${ }^{(131)}$.

\section{La llegada del robot}

La idea del autómata tiene orígenes remotos y se mantuvo en el tiempo, alcanzando esplendor con el capitalismo. Los autómatas o robots -no siempre se consideran sinónimosse encuentran en el Talmud (leyenda del Golem), en la Ilíada y en distintos momentos históricos, en los que se buscan construir dispositivos automáticos que ayuden y/o sustituyan a las personas en los procesos de trabajo ${ }^{(128)}$.

Una historia poco conocida es la de René Descartes y su única hija, Francine, la cual muere por escarlatina, en 1640, a la edad de 5 años. Ante el dolor, la respuesta del padre fue la de construir un autómata. Para ello, le pidió a un artesano una máscara de cerámica con el rostro de la niña y, con piezas de metal y relojería, construyó el autómata del tamaño de Francine, que además emitía sonidos similares a los humanos. Así, el filósofo de la modernidad, el hombre de la razón, suplantó a su hija muerta con un autómata, al que guardaba y transportaba en un baúl y, una vez a solas, la sacaba del baúl para compartir con "ella" su cotidiano, y comentarle ideas y proyectos ${ }^{(132)}$.

A mediados del siglo $X X$, el inicio de la microelectrónica y las máquinas inteligentes, dio lugar a la robótica en la práctica médica ${ }^{(128)}$. Un ejemplo de su impacto actual se encuentra en la corporación Intuitive Surgical, que fabrica sistemas quirúrgicos robóticos, especialmente, el sistema da Vinci, el cual ha recibido la aprobación regulatoria para ser utilizado en procedimientos de cirugía en seis continentes (64 países), con más de 3.660 robots quirúrgicos y más de 3 millones de pacientes de urología, ginecología, cirugía general, cirugía pediátrica, cirugía torácica, cirugía cardíaca, y otorrinolaringología ${ }^{(133)}$.

La asociación entre robótica e inteligencia artificial no deja de sorprendernos día a día. Pero, aun así, ¿podemos pensar a los robots interactuando con pacientes, interpretando signos, síntomas y subjetividades? Parece imposible pero, entonces, ¿cómo pensar esa interacción entre profesionales y sujetos que padecen? Los modelos dominantes de atención se alejan de la humanización, lo cual se expresa hasta en los relatos de médicos que han atravesado una internación hospitalaria $^{(134,135)}$. Entonces, nos preguntamos ¿podemos avanzar hacia el derecho a la atención de la enfermedad basado en relaciones sustentadas en el reconocimiento del otro, en el marco de vínculos que superen el "orden médico" y sus modelos de atención, sin perder calidad científica?

Mientras en la infancia los autómatas son juguetes deseados y se presentan como representaciones del mundo real, en la vida adulta representan una realidad opresiva. Para Walter Benjamin, el proceso de mecanización se 
centra en la idea de que la máquina puede hacerlo todo y oculta el hecho de que provoca atrofia, no solo muscular, sino intelectual. Para Benjamin, las máquinas empobrecen el comportamiento humano, y afirma que los seres humanos "viven su existencia como autómatas [...] prefiguración de la inhumanidad futura"(136).

\section{La profesión médica}

Para Sennett, el primer uso moderno de la palabra profesional refiere a personas que se consideraban diferentes a ser simples empleados $^{(128)}$. Freidson encuentra dificultades en definir qué es una profesión, pero en la duda afirma "si alguna cosa es la profesión, esa cosa es la medicina contemporánea"(18). Basa su afirmación en la posición de la medicina en las sociedades a partir de la segunda mitad del siglo XIX, cuando se asemeja a las antiguas religiones de Estado, al poseer el monopolio de definir qué es salud y qué es enfermedad, con muy alta legitimidad, al punto de recibir el legado de la cura por parte del Estado, que -independientemente de la dirección política- deja en manos de los médicos el aspecto técnico de su trabajo ${ }^{(18,71)}$.

Eliot Freidson reconoce que la medicina, en tanto profesión, tiene la particularidad de que su trabajo se realiza en la intimidad de un consultorio, que se limita -por lo general- a una relación -no necesariamente armónica- entre dos personas, pero que a diferencia de otras profesiones -cuyas acciones son más colectivas- la medicina puede quedar eximida de la influencia de los intereses del juego social ${ }^{(18,71)}$.

Es por ello que, mientras en el siglo XX se asistía socialmente a una retirada del ejercicio individual de lo profesional, y su lugar era tomado por distintas formas organizativas, la medicina aprovechó su autonomía y logró constituirse en una excepción entre las profesiones, ya que no solo escapó a los mecanismos de control de esas formas organizativas, sino que se apropió de instituciones como los hospitales, lo cual restringió las posibilidades de regulación de sus prácticas.
Desde fines del siglo XIX, la conformación de hegemonía a partir de las "libertades médicas" constituyó uno de los pilares de sus asociaciones gremiales - no solo de EEUU-, las cuales se basaron en la libre prescripción, el pago por acto médico y la libertad de elección por parte del paciente ${ }^{(1,137)}$. Todo ello permitió la autonomía de los médicos frente al poder político y fundamentó su reclamo a participar en la formulación de políticas y en la dirección de las organizaciones, a la vez que negó esa posibilidad a otras profesiones ${ }^{(1,18)}$. Esa hegemonía comienza a eclipsarse a partir de la década de 1980, con el ingreso del capital financiero y la conformación del complejo médico industrial. Como señala Paul Starr "la amenaza principal a la soberanía de la profesión residía precisamente en su éxito"(1).

¿Qué se entiende por un buen trabajo médico?, ¿cuál es su esencia?, ¿tenemos respuestas comprensibles para no expertos, de manera que el Estado pueda regularlo y las comunidades puedan controlarlo? Esa pericia sociable, debiera orientarse hacia las personas, en un lenguaje claro y accesible. Por el contrario, la pericia antisocial, va a generar una brecha entre el conocimiento y la habilidad del experto y el no experto.

\section{¿La vuelta del arte-sano?}

El taller era el hogar del artesano, allí convivían tres jerarquías: el maestro, los oficiales y los aprendices. Todos trabajaban juntos, pero no como iguales. El taller era el espacio donde se evidenciaba la disputa entre autoridad y autonomía. La autoridad residía en las habilidades del maestro, inseparables de su ética, lo cual se legitimaba por la transferencia de esas habilidades a oficiales y aprendices. El maestro definía cuál era el trabajo, el cual se realizaba bajo su dirección, que constituía una figura casi paterna ${ }^{(128)}$. El artesano enseñaba a través de ejemplos, el principio de su instrucción era mostrar, no hablar, pero dada la magnitud del abismo entre el lenguaje y el cuerpo, el movimiento corporal aparecía como fundante del lenguaje ${ }^{(128)}$. El aprendiz ingresaba al taller y, bajo juramento religioso, prometía no develar los secretos 
del maestro y permanecer cerca de él durante el trabajo. Tenía un tiempo de formación, en general de siete años, el cual finalizaba con la presentación de una obra basada en la imitación y la copia, en la que debía demostrar el manejo de las habilidades. Si el aprendiz pasaba a oficial, podía permanecer como tal, entre cinco y diez años más. Para pasar a ser maestro, y transformarse en juez de todo ese proceso, debía demostrar capacidad de gestión y confiabilidad en tanto líder, además de realizar una obra maestra superior. Los veredictos de los maestros eran inapelables, muy rara vez el gremio (conjunto de artesanos) debía intervenir ${ }^{(128)}$. Resultan evidentes las semejanzas con las lógicas vigentes en las universidades, con sus cátedras y sus profesores titulares y ayudantes; con las carreras de investigadores en las instituciones científicas y con la formación académica de posgrado y/o las residencias profesionales. Todas ellas reproducen en buena parte lo descripto en la edad media como trabajo artesanal, pero desconocen esa relación.

Richard Sennett retoma de la Enciclopedie la importancia del trabajo artesanal en tanto trabajo bien hecho, y a la artesanía como "un impulso humano duradero y básico, que consiste en el deseo de realizar bien una tarea, sin más", es decir, dedicarse a hacer bien el trabajo, lo cual expresa tener curiosidad, investigar y aprender ${ }^{(128)}$.

Este texto no plantea lo artesanal desde una concepción romántica, tal como Fernando Diéz Rodríguez le atribuye a las propuestas de John Ruskin y William Morris en el campo del trabajo en general ${ }^{(3)}$, ni propone una vuelta al pasado, sino que lo proyecta como una superación de lo que hoy representa el trabajo médico, en el sentido dialéctico que aprendimos de Juan Samaja (suprimir-conservar-superar) $(138,139)$. Es por todo lo anterior, que proponemos llamar arte-sano al trabajador de la salud, no en el sentido de que todo su trabajo sea artesanal, desconociendo los adelantos científicos y/o tecnológicos, sino que su trabajo esté basado en lo relacional, sin menoscabo de la calidad científica. Así se recupera la dimensión de "arte" que la medicina reconocía como parte de su trabajo y que fue anulada por la revolución tecnológica ${ }^{(65)}$. Esos arte-sanos son fundamentales para la salud de una sociedad, ya que como señalara Henry Sigerist: "no son ciertamente los grandes médicos los que determinan el estado sanitario de una población, sino el ejército de los médicos prácticos que, dispersos por todo el país, se hallan al lado del enfermo"(140). Sigerist refuerza esa idea proponiendo que el médico no dependa económicamente del paciente y, por lo tanto, no se vea obligado a lucrar con la enfermedad y el sufrimiento, sino que debería estar asalariado, oponiéndose al ejercicio liberal de la profesión ${ }^{(70)}$.

Hoy, la diferencia entre un estudiante de medicina brillante y un médico experimentado radica en que este último es más preciso en sus diagnósticos ya que es menos formalista, actúa de manera más receptiva teniendo en cuenta la singularidad del paciente, en cambio el joven será más formalista tratando de entender las situaciones en una lógica de causa-efecto y no de manera procesual. Esa experiencia artesanal con herramientas imperfectas se entiende en la comprensión de la pericia sociable, que nuclea en el experto no solo la capacidad de producir, sino de reparar que, en el caso de la práctica médica, es la capacidad no solo de la atención, sino también y, sobre todo, la de cuidar ${ }^{(141)}$.

“¿Cuál es la innovación tecnológica más importante de los últimos años en la medicina?", le preguntaron al gran médico español Gregorio Marañón (1887-1990), quién respondió: "la mejor herramienta del médico es la silla", en alusión al poder escuchar al paciente. "Cuidar, curar..., tal vez", repetía Carlos Gianantonio (1926-1995) considerado el padre de la pediatría argentina.

Para Richard Sennett, hacer es pensar, en contraposición al legado "primero se hace y luego se piensa". Pensarse como trabajadores artesanales y no industriales tiene implicancias personales y sociales ${ }^{(128)}$. Las personas que producen cosas no siempre comprenden lo que hacen, como tampoco, siempre son dueñas de lo que hacen. Tienen un conocimiento tácito, saben cómo hacer las cosas, pero no pueden verbalizar eso que saben. No sufren tanto por el trabajo que hacen, sino por la forma en que 
están organizados y piensan la organización. Una manera rígida y racional cristaliza sus pensamientos sobre la organización, sin darse cuenta de que deben jugar en esos espacios transicionales que la organización va creando, pero como lo ignoran solo pueden hacer lo que saben ${ }^{(128,142)}$. Richard Sennett retoma de John Dewey la afirmación "el trabajo que se mantiene impregnado de juego es arte", y con ello recupera el juego como un elemento central de la cultura ${ }^{(128,143,144)}$.

La pregunta que cabe a cada trabajador y a sus colectivos es: ¿cómo nos producimos como sujetos en el trabajo de cuidar? y ¿Cómo cuidamos de las personas que sufren? Una respuesta posible sería entender que hacer más y mejor es hacer diferente.

\section{UNA INSTITUCIONALIDAD NEGADA: LOS CENTROS DE SALUD}

Los centros de salud reciben múltiples denominaciones a lo largo de la historia que, en general, conviven en el tiempo. Por ejemplo, en Argentina, se los conoce como centro de salud, centro periférico, dispensario, sala de primeros auxilios, posta sanitaria, salita o unidad de pronta atención (UPA). Esto nos señala que las instituciones incluyen no solo reglas, sino también una semiótica que construye una trama de significados y sentidos que guía las acciones y las interpretaciones de los sujetos (individuales y colectivos). Por el contrario, el hospital conserva en el tiempo su nombre y solo cambian los adjetivos que lo acompañan, pero esos adjetivos no afectan su identidad.

En EEUU, los dispensarios públicos se fundan a fines del siglo XVIII en Filadelfia, Nueva York, Boston y Baltimore, y crecieron lentamente en el siglo siguiente. En sus inicios, estuvieron destinados a dar prestaciones y medicinas de elaboración casera a pacientes pobres, basados en las ideas de caridad. También cumplían un rol muy importante en la enseñanza a los estudiantes de medicina, lo que constituyó la causa de su expansión, dadas las necesidades de lugares de prácticas para los futuros médicos. Pero ese crecimiento de los dispensarios trajo conflictos entre lo público y lo privado(1). Así un médico general, escribía:

\begin{abstract}
Si un médico atiende una clínica tres veces a la semana durante 52 semanas, tratando diariamente un promedio de cinco pacientes, cada uno de los cuales podría pagar una suma moderada, digamos un dólar (aunque esta suma es un promedio pequeño), ¿qué ha hecho ese médico? Simplemente privó a la profesión de 780 dólares en un año. ${ }^{(1)}$
\end{abstract}

El temor a que los dispensarios fueran utilizados por personas en condiciones de pagar una consulta llevó a la incorporación de los trabajadores sociales para controlar y evitar ese "abuso"(1). En varios estudios se demostró que entre un $2 \%$ y un $12 \%$ (como máximo) de las personas que acudían al centro de salud podrían haber pagado la consulta ${ }^{(1,66)}$. El temor al abuso de los pacientes en el uso de los dispensarios ocultó otro abuso: el de los profesionales, los cuales no siempre atendían de la mejor forma y exponían a las personas a largas esperas. Los médicos especialistas, a diferencia de los generales, defendieron las prácticas en los dispensarios, ya que era el lugar para adquirir experiencia y desarrollar experimentos. Los pacientes, desde entonces, carecen de defensores.

En las primeras décadas del siglo XX se originó el movimiento de los centros vecinales de salud, que alcanzó su auge en la década de 1930, para posteriormente decaer ${ }^{(66)}$. Ese movimiento se caracterizó por brindar acceso a todos los servicios ambulatorios, contar con personal calificado, alcanzar altos niveles de participación de la población asistida y tener una fuerte articulación con otros recursos de la comunidad ${ }^{(66)}$. Ese movimiento representó una respuesta ante el bajo impacto de los programas gubernamentales, y el aumento de la población por las corrientes migratorias -sobre todo de Europa- que no estaban calificadas laboralmente y se sumaron al desarrollo industrial y comercial en 
calidad de obreros o artesanos ${ }^{(66)}$. El desconocimiento del idioma nativo, la pobreza y las malas condiciones laborales originaron barrios donde se concentraron los inmigrantes por nacionalidades o etnias, y surgieron formas solidarias que resguardaron sus culturas identitarias ${ }^{(66)}$. Todo ese movimiento social y sus condiciones de vida ocasionaron el rechazo y la preocupación de gran parte de la sociedad americana, que veía en los inmigrantes una amenaza a sus estilos de vida. Esa situación social fue problematizada por los trabajadores sociales, que fueron los primeros en ocuparse de los migrantes, y en señalar el rol de la pobreza como determinación de los problemas existentes, lo cual no niega el carácter moralizante de muchas de sus acciones ${ }^{(66)}$.

La primera respuesta desde el Estado fue el desarrollo de nuevos programas que acompañaban la producción de conocimientos, en los que no solo tomaba relevancia el medioambiente, sino la salud individual. Todo esto confluía en un incremento del personal capacitado ${ }^{(66)}$. La implementación de los programas trajo otros problemas: falta de coordinación de las acciones programáticas; superposición de acciones sobre la misma población; lejanía con las poblaciones que se pretendían atender; multiplicidad de agencias descoordinadas; reconocimiento que los problemas de esas poblaciones no eran simples, ni las soluciones fáciles; desconocimiento por parte del ciudadano común de la existencia de los programas y los servicios que prestaban, y dónde podía conseguir$\operatorname{los}^{(66)}$. En 1914, el comisionado de salud de Nueva York señalaba: "diversas oficinas envían a sus representantes al mismo distrito, incluso a veces a la misma casa, con el resultado de una pérdida indebida de tiempo y energía en perjuicio de los ciudadanos"(66). Nada ha cambiado desde entonces con relación a las estructuras programáticas y la frase del comisionado mantiene vigencia ${ }^{(145)}$.

Las descripciones anteriores abonaron la idea de que las prestaciones médicas y la asistencia social deberían brindarse en un mismo lugar. La necesidad de la proximidad de los centros de salud a las poblaciones respondió a las características culturales de los migrantes, sobre todo, de la mujer. Los tiempos de espera prolongados, la necesidad del cuidado de sus hijos y las barreras idiomáticas dificultaban su asistencia a los centros de atención, lo cual afectaba no solo su salud, sino que los programas oficiales perdían el contacto con ese agente central para la salud del grupo familiar ${ }^{(66)}$.

En 1911, la atención de la población materno-infantil se realizó en un "plan por manzana" con migrantes polacos, que se transformó en una experiencia relevante. Se tomaron 33 manzanas, con 16.000 personas y unas 350-400 madres con hijos ${ }^{(66)}$. Esa experiencia fue corta y pudo ser reeditada en 1917 en una organización comunitaria que tenía, además, el control sobre los problemas que la aquejaban ${ }^{(66)}$. Toda acción en esas comunidades era previamente aprobada por las personas del distrito. Estas experiencias -en un área de New York- fueron muy interesantes como democracias locales (autogobierno) en el manejo del tema de la salud ${ }^{(66)}$. Aunque no todo fueron flores. La oposición surgió del alcalde, el director de beneficencia pública y grupos conservadores que veían allí un "complot rojo" y todo terminó en 1920. Luego se sucedieron otras experiencias que tomaron diferentes problemas, pero siempre se mostraron muy lábiles a los cambios políticos y, por ende, tampoco consiguieron persistir en el tiempo.

La reforma flexneriana ${ }^{(18)}$ puso un límite al crecimiento de los dispensarios que se habían expandido por la proliferación de las escuelas de medicina. Fue entonces que los dispensarios comenzaron a transformarse en departamentos de consulta externa en los hospitales y, a partir de 1920, iniciaron el cobro de la consulta(1).

La fortaleza y estabilidad del hospital en la historia -basada en el poder médicocontrasta con la fragilidad de los centros de salud, no obstante, se fueron replicando en otras ciudades. Winslow, en 1919, afirmó que los centros de salud constituían el acontecimiento más notable en la evolución de la salud pública de EEUU ${ }^{(66)}$.

En 1920 el Ministerio de Salud de Gran Bretaña presentó el "Informe sobre el futuro 
de los servicios médicos y afines", conocido como el "Informe Dawson" en el que se asignaba un rol central a los centros de salud ${ }^{(146)}$. El Informe redactado en el clima de posguerra de la Primera Guerra Mundial, tiene 38 carillas, dividas en siete secciones, en las que cabe destacar la ausencia de la palabra hospital en los títulos, y solo se encuentra al interior de la sección $\mathrm{V}$, ocupando menos de dos carillas ${ }^{(146)}$.

El fin de la Primera Guerra Mundial habilitó un gran desarrollo de los centros de salud con fuerte apoyo de la Cruz Roja estadounidense. A comienzos de 1920, en EEUU había 72 centros en 49 comunidades; siete ciudades tenían más de uno; 33 estaban bajo la administración pública; 27 bajo control privado y 16 con administración mixta; y la Cruz Roja participaba en 19 de ellos ${ }^{(66)}$. En 1930, eran 1.511 centros, su principal financiamiento era público, y sus acciones básicamente preventivas. En 1932, William Welch, desde la Escuela de Salud Pública de la Universidad de Johns Hopkins, crea en Baltimore, los Distritos de Salud, que amplían su cobertura geográfica e incluyen los servicios de atención ${ }^{(66)}$. El crecimiento del número de centros de salud puede ser considerado exitoso, pero también fue motivo de su decadencia, ya que bajo su nombre se realizaron acciones muy disímiles que terminaron por desprestigiarlos ${ }^{(66)}$.

En 1927, Michael Davis definió al centro de salud como "una organización que proporciona, promueve y coordina servicios médicos y servicios sociales relacionados, en un distrito determinado". Esto fue más un deseo que una realidad. Muy rara vez se incorporó la atención médica, por cuya razón la expresión "centro de salud" se aplicó indistintamente a guarderías infantiles, casas de descanso, departamentos hospitalarios para pacientes no internados y clínicas de tuberculosis y enfermedades venéreas. Por consiguiente, las estadísticas que sugieren que hubo cientos de estos centros deben verse con escepticismo. ${ }^{(1)}$
George Rosen entiende que, en EEUU, el declive de los centros de salud se debió de manera indirecta a la disminución de la pobreza (después de todo habían sido diseñados para dar respuesta a la enfermedades de los pobres); las restricciones migratorias; la inclusión en la sociedad de esos hijos de inmigrantes que dominaban el idioma y los valores culturales estadounidenses; la falta de integración en los centros de salud de las acciones preventivas con las curativas; la pérdida por parte del trabajo social de la mirada comunitaria para pasar a enfocarse en los casos individuales, y -no por último menor- la resistencia de grupos políticos, de médicos y de las mismas organizaciones de beneficencia ${ }^{(66)}$.

En 1946, los centros de salud tuvieron un nuevo empuje por parte de John Grant, funcionario de la Fundación Rockefeller, quien planteó que el centro de salud del futuro se estaba por crear $^{(66)}$. El mismo Grant impulsó a fines de la década de 1960, la traducción y publicación por parte de la Organización Panamericana de la Salud de una versión en español del Informe Dawson ${ }^{(147)}$.

En 1952, Henry Sigerist ${ }^{(148)}$ dicta cinco conferencias en la Escuela de Higiene y Medicina Tropical de la Universidad de Londres. Para entonces, él ya había cambiado su idea sobre los seguros de salud, a los que ahora consideraba "rígidos y en manos de intereses creados" con un "tipo de servicio médico hipertrofiado", de allí la necesidad de "buscar nuevos caminos". En una de esas conferencias titulada "Los modelos cambiantes de la atención médica" afirma:

El mejor modo de emplear a fondo la actual tecnología médica es organizar grupos médicos, equipos que ejerzan en centros de salud. Lo que más necesita una familia no es un médico familiar sino un centro de salud. Estos centros deben estar cerca de la gente. En las zonas industriales pueden estar al servicio de una fábrica o de un grupo de fábricas, o de un distrito residencial. La elección totalmente libre de médicos es una ficción. En zonas rurales no hay 
gran posibilidad de elección, y ¿cómo hace la gente en las ciudades para elegir su médico? La gente tiene como norma ir al médico del vecindario, al médico que puede permitirse; y en las áreas de consulta externa de un hospital tampoco hay posibilidad de elegir; puede que sea atendido por un estudiante avanzado de medicina. ${ }^{(149)}$

En 1970, el presidente de la AMA, frente a las críticas al poder médico sostuvo: "La medicina organizada no debe concentrarse únicamente en los intereses privados de sus miembros [...] Debe preocuparse, y se preocupa, por cuestiones sociales tales como la educación sexual, el alcoholismo, la contaminación del aire"(1). En 1971, 19 años después de la conferencia de Henry Sigerist, la AMA Ilama a apoyar los centros de salud vecinales, dado que allí se podría pagar a los profesionales sus honorarios por servicio, salario, o capitación según ellos mismos decidieran, y propone: "Si logramos devolver la amplia atención médica a los centros de población, a los vecindarios, y si proporcionamos atención médica 24 horas diarias, siete días a la semana, el pueblo dirá al Congreso que el sistema actual no necesita ser reestructurado"(1). Que la AMA aceptara otras formas de pago del trabajo médico, y recuperara los centros de salud, da cuenta de la amenaza que sentía la corporación médica estadounidense ante el complejo médico industrial y el malestar y las denuncias de la sociedad civil y movimientos sociales ante el poder médico.

La promesa de la Declaración de Alma Ata en 1978, de una atención integral e integrada, que jerarquizaría el primer nivel de atención se evaporó como el vodka que acompañó su celebración. Solo nos queda la certeza de la pregunta -no inocente- de Mario Testa sobre si la declaración proponía ¿atención primaria o primitiva de salud?(54). Los centros de salud en EEUU -como bien señala George Rosen- fueron funcionales para dar respuestas a situaciones de pobreza del momento, no más que eso, ya que la medicina tenía su futuro en los mercados florecientes que se comenzaban a construir y que tenían en el hospital la sede de esa nueva industria médica ${ }^{(67)}$.

El devenir de los centros de salud en EEUU resulta muy conocido para los trabajadores de la salud de la mayoría de los países de América Latina, independientemente de haber leído o no el texto de George Rosen ${ }^{(66)}$, ya que lo han vivenciado en algún momento de su vida laboral. Quizá sorprenda que haya ocurrido en EEUU en las primeras décadas del siglo pasado y que guarde tanta semejanza con experiencias realizadas en distintos países de América Latina, aun en la actualidad.

Las evidencias señalan que los centros de salud son el lugar natural donde los artesanos deberían ejercer sus prácticas. Como bien señalaba José Renán Esquivel -padre de la pediatría panameña-, "las enfermedades no están en los hospitales, están en las comunidades"(150). Por lo tanto, nos preguntamos: ¿es posible la deconstrucción de la cultura hospitalocéntrica?; ¿por qué no volver a relaciones comunales, en las que los centros de salud sean las nuevas ciudadelas de ciencia y relaciones humanas personalizadas con los distintos colectivos que pertenecen a los territorios?; ¿se podrá transformar el gasto en salud en una inversión social? Todas estas preguntas son débiles en la agenda pública, lo cual no niega la existencia de numerosas experiencias que, en distintos momentos, trataron (y tratan) de avanzar en ese sentido.

\section{REFLEXIONES FINALES: UNA ENCRUCIJADA DE DIFÍCIL RESOLUCIÓN}

¿Por qué la promesa de un futuro sin enfermedades no solo no se cumplió, sino que la ciencia llegó a inventarlas? La matriz de la razón moderna y sus ideas de progreso y riqueza se basaron en la ciencia y la tecnología. Ese proceso de racionalización impactó en la acción social, volviéndola más instrumental (conocimientos técnicos), limitando la humanización y produciendo, frente a la ilusión de 
un futuro mejor, el desencanto; lo cual expresa el reverso siniestro de la promesa del progreso $^{(11,151)}$.

Por ello, es necesario incorporar al análisis dimensiones ideológico-culturales que nos permitan entender cómo la medicina en EEUU pasó desde mediados del siglo XIX -en donde era una práctica sin actores, sin instituciones relevantes y con baja legitimidad-a constituirse a mediados del siglo XX, en una corporación muy poderosa, imposible de ser regulada y con alto consenso social ${ }^{(1)}$. Hay que ver en todo esto, no solo el desarrollo de una profesión (la médica) y de una institución (el hospital), sino también una profunda revolución cultural que involucró situaciones como el nacer, el morir, el control de los cuerpos, y la atención y el cuidado de los sujetos con padecimientos ${ }^{(1)}$. En todo el proceso, la medicina se transformó en un campo extremadamente complejo, conformado por intereses y capitales respaldados en conocimientos especializados, técnicas y concepciones sobre lo "normal", que construyeron la idea de la salud como una cuestión de la vida privada ${ }^{(1)}$. Esa transformación se orientó a un predomino de lo terapéutico sobre la prevención y la promoción, lo cual impulsó a la institución hospital como el lugar más apropiado para la atención de las personas y sus padecimientos ${ }^{(1)}$. Todo esto coloca a los profesionales de la salud en la encrucijada de brindar servicios solo a quienes pueden pagarlo, o a quienes los necesitan; disyuntiva que no debe limitarse a dichos profesionales, sino que exige un amplio debate social.

\section{AGRADECIMIENTOS}

Agradezco los comentarios y sugerencias recibidos por Jorge Arakaki, Damián Herkovits y Lillia Blima Schraiber. Y a Ana Ortigoza por su colaboración en la recopilación de los datos de la Tabla 1.

\section{REFERENCIAS BIBLIOGRÁFICAS}

1. Starr P. La transformación social de la medicina en los Estados Unidos de América. México DF: Fondo de Cultura Económica; 1991.

2. Arendt H. La condición humana. Buenos Aires: PAIDOS; 2003.

3. Diez Rodriguez F. Homo Faber: historia intelectual del trabajo 1675-1945. Madrid: Siglo XXI Editores; 2014.

4. Coriat B. El taller y el robot: ensayos sobre el fordismo y la producción en masa en la era de la electrónica. México DF: Siglo XXI Editores; 1996.
5. Berger $P$, Luckmann T. La construcción social de la realidad. Buenos Aires: Amorrortu; 1993.

6. Bourdieu P, Wacquant L. Una invitación a la sociología reflexiva. Buenos Aires: Siglo XXI Editores; 2009.

7. Bourdieu P, Wacquant L. Respuestas: por una antropología reflexiva. México DF: Grijalbo; 1995.

8. Canguilhem G. Lo normal y lo patológico. México DF: Siglo XXI Editores; 1986.

9. Spinelli H. El trabajo en el campo de la salud: ¿modelos artesanales o industriales? Investigación y Educación en Enfermería. 2015;33(2):194-205.

10. Spinelli $H$. Las dimensiones del campo de la salud en Argentina. Salud Colectiva. 2010;6(3):275293.

11. Giddens A, Sutton PW. Sociología. Madrid: Alianza; 2012. 
12. Merhy E. Salud: cartografía del trabajo vivo. Buenos Aires: Lugar Editorial; 2006.

13. Franco T, Andrade CS, Ferreira VSC, (eds.). A produção subjetiva do cuidado: cartografias da estratégia saúde da família. São Paulo: Editora Hucitec; 2009.

14. Rosanvallon P. La nueva cuestión social: repensar el Estado providencia. Buenos Aires: Manantial; 1995.

15. Fleury S. Estado sin ciudadanos: seguridad social en América Latina. Buenos Aires: Lugar Editorial; 1997.

16. Belmartino S. Desarrollo metodológico para una historia comparada de la profesión médica. Buenos Aires: CIEPP; 2011.

17. Goldmann L. Introducción a la filosofía de Kant: hombre, comunidad y mundo. Buenos Aires: Amorrortu; 1998.

18. Freidson E. Profissão médica: um estudo de sociología do conhecimento aplicado. São Paulo: Editora UNESP; 2008.

19. González Leandri R. Curar, persuadir, gobernar: la construcción histórica de la profesión médica en Buenos Aires, 1852-1886. Madrid: Consejo Superior de Investigaciones Científicas, Centro de Estudios Históricos; 1999.

20. Weber M. Economía y sociedad. México DF: Fondo de Cultura Económica; 1992.

21. Chiavenato I. Introducción a la teoría general de la administración. 7a ed. México DF: McGrawHill; 2007.

22. Flexner A. Medical education in the United States and Canada [Internet]. New York: Carnegie Foundation for the Advancement of Teaching; 1910 [citado 10 may 2018]. Disponible en: https:// tinyurl.com/nk62c73.

23. Hoffman B. Health care for some: rights and rationing in the United States since 1930. Chicago: The University of Chicago Press; 2013.

24. Banco Mundial. Informe sobre el desarrollo mundial 1993: invertir en salud. Washington DC: Banco Mundial; 1993.

25. Relman AS. The new medical-industrial complex. New England Journal of Medicine. 1980;303(17): 963-970.

26. Shryock R. The history of quantification in medical science. En: Quantification: A history of the meaning of measurement in the natural and social sciences. New York: Bobbs Merrill; 1961. p. 85-107.

27. Spinelli H. Razón, salud y violencia o la (im)potencia de la racionalidad médico-científica. [Tesis de doctorado]. Campinas: UNICAMP; 1998.

28. Bernal J. La ciencia en la historia. México DF: Nueva Imagen; 1985.

29. Tamayo Pérez R. El concepto de enfermedad, su evolución a través de la historia. México DF: Fondo de Cultura Económica, Facultad de Medicina, UNAM, Consejo Nacional de Ciencia y Tecnología; 1988.

30. Papp D. Visión sinóptica de la ciencia del Barroco. En: Laín EP. Historia universal de la medicina. Barcelona: Salvat; 1972. p. 199-214.

31. Illich I. Némesis médica. México DF: Planeta; 1976.

32. Harvey G. De motu cordis. Buenos Aires: EUDEBA; 1970.

33. Crombie A. Historia de la ciencia: de San Agustín a Galileo: 2; Siglos XIII-XV. Madrid: Alianza Editorial; 1959.

34. Asimov I. Breve historia de la biología. Buenos Aires: EUDEBA; 1964.

35. Mettrie L. El hombre máquina. Buenos Aires: EUDEBA; 1961.

36. Aguilar M. Descartes y el cuerpo máquina. Pensamiento. 2010;66(249):755-770.

37. Basalla G. La evolución de la tecnología. México: Grijalbo; 1991.

38. Donatelli M. O estudo da medicina em Descartes. Ideaçâo. 1999;(4):125-140.

39. Donatelli M. Descartes e os médicos. Scientiae Studia. 2003;1(3):323-336.

40. Shapin S. Descartes the doctor: rationalism and its therapies. British Journal for the History of Science. 2000;33(2):131-154.

41. Descartes R. Discurso del método: estudio preliminar. Madrid: Tecnos; 2003.

42. Kuhn T. La estructura de las revoluciones científicas. México DF: Fondo de Cultura Económica; 1991.

43. Donnangelo MCF. Medicina \& sociedade. São Paulo: Hucitec 2011. 
44. Canguilhem G. El conocimiento de la vida. Barcelona: Anagrama; 1976.

45. Foucault M. Historia de la sexualidad 1: la voluntad de saber. Buenos Aires: Siglo XXI Editores; 2014.

46. Clavreul J. El orden médico. Barcelona: Argot; 1983.

47. Canguilhem G. Ideología y racionalidad en la historia de las ciencias de la vida: nuevos estudios de historia y filosofía de las ciencias. Buenos Aires: Amorrortu; 2005.

48. Testa M. Saber en salud. Buenos Aires: Lugar Editorial; 1997.

49. Bertalanffy L. Teoría general de los sistemas: fundamentos, desarrollo, aplicaciones. México DF: Fondo de Cultura Económica; 1995.

50. Maturana $H$, Varela F. De máquinas y seres vivos: autopoiesis, la organización de lo vivo. Buenos Aires: Lumen; 2003.

51. Maturana H, Varela F, Uribe R. Autopoiesis the organization of living systems, its characterization and a model. Biosystems. 1974;5(4):187-196.

52. Maddox J. Towards synthetic self-replication. Nature. 1991;354:351.

53. Flores F. Inventando la empresa del siglo XXI. Santiago de Chile: Dolmen; 1989.

54. Testa M. Pensar en salud. Buenos Aires: Lugar Editorial; 1993.

55. Heidegger M. ¿Qué significa pensar? Madrid: Trotta; 2010.

56. Roemer M. Perspectiva mundial de los sistemas de salud. México DF: Siglo XXI Editores; 1980.

57. Rosen G. The hospital: historical sociology of a community institution. En: The hospital in Modern Society. New York: The Free Press of Glencoe; 1963. p. 1-36.

58. Freeman $H$, Levine $S$, Reeder L. Manual de sociología médica. México DF: Fondo de Cultura Económica; 1998.

59. Foucault M. Historia de la medicalización. En: La vida de los hombres infames. México DF: Altamira; 1992.

60. Foucault M. Incorporación del hospital a la tecnología moderna. En: La vida de los hombres infames. Buenos Aires: Altamira; 1992. p. 153-173.
61. Foucault M. La crisis de la medicina o la crisis de la antimedicina. En: La vida de los hombres infames. Buenos Aires: Altamira; 1992.

62. Foucault M. Nacimiento de la biopolítica. Buenos Aires: Fondo de Cultura Económica; 2007.

63. Castro E. El vocabulario de Michel Foucault: Un recorrido alfabético por sus temas, conceptos y autores. Bernal: Prometeo, Universidad de Quilmes; 2004.

64. Foucault M. El nacimiento de la clínica. México DF: Siglo XXI Editores; 1986.

65. Reiser S. La medicina y el imperio de la tecnología. México DF: Fondo de Cultura Económica; 1990.

66. Rosen G. De la policía médica a la medicina social. México DF: Siglo XXI Editores; 1985.

67. Rosen G. Uma história da Saúde Pública. São Paulo: Hucitec, Abrasco, UNESP; 1994.

68. Belmartino S. Historias de la profesión médica: Argentina y Estados Unidos en el siglo XX. Salud Colectiva. 2010;6(3):329-356.

69. Berliner H. A larger perspective on the Flexner report. International Journal of Health Services. 1975;5(4):573-592.

70. Sigerist $\mathrm{H}$. Historia y sociología de la medicina: selecciones. Bogotá: Universidad Nacional de Colombia; 2007.

71. Freidson E. La organización de la práctica médica. En: Freeman HE, Levine S, Reeder GL, compiladores. Manual de sociología médica. México DF: Fondo de Cultura Económica; 1998. p. 399413.

72. Sultz H, Young K. Health Care USA: understanding its organization and delivery. 7a ed. Massachusetts: Jones \& Bartlett; 2010.

73. Freidson E. The hospital in modern society. New York: Free Press of Glencoe; 1963.

74. Alison Glover J. La incidencia de tonsilectomía en niños en edad escolar. En: Investigación sobre servicios de salud: una antología. Washington DC: OPS; 1992. p. 18-31.

75. Hoge VM. The hospital survey and construction act. Social Security. 1946;9(10):15-17.

76. Viel B. La medicina socializada y su aplicación en Gran Bretaña, Unión Soviética y Chile. Santiago de Chile: Universidad de Chile; 1961. 
77. Haldeman J, Abdellah F. Concepts of progressive patient care. Hospitals. 1959;33(11):41-46.

78. Thoms EJ. Progressive patient care: Planning and research. New York State Journal of Medicine. 1959;59(14):2777-2781.

79. Belmartino S. Historias comparadas de la profesión médica: Argentina y EEUU. Buenos Aires: CIEPP, Miño y Dávila; 2011.

80. Catlin AC, Cowan CA. History of health spending in the United States, 1960-2013 [Internet]. 2015 [citado 13 jun 2017]. Disponible en: https://tinyurl.com/gn7oo36.

81. Hartman M, Martín A, Nuccio O, Catlin AC. Health spending growth at a historic low in 2008. Health Affairs. 2010;29:147-155.

82. Diez Roux A, Spinelli H. El sistema de salud de Estados Unidos: ¿paradigma o espejismo? Cuadernos Medico Sociales. 1993;(63):9-16.

83. Organización Panamericana de la Salud. Las condiciones de salud en las Américas, edición de 1990. Washington DC: OPS; 1990.

84. Schraiber L. O médico e suas interações: a crise dos vínculos de confiança. São Paulo: Hucitec; 2008.

85. Health Forum. AHA hospital statistics, 2018 edition. Chicago: American Hospital Association; 2018.

86. Statita. Hospital care expenditure in the United States from 1960 to 2018 (in billion U.S. dollars) [Internet]. 2018 [citado 10 jun 2018]. Disponible en: https://tinyurl.com/y9ltasnj.

87. National Center for Health Statistics. Health, United States, 2016: With chartbook on long-term trends in health. Hyattsville: US Department of Health and Human Services; 2017.

88. Andreazi M, Kornis MG. Padrões de acumulação setorial e serviços nas transfrormações contemporáneas da saude. Ciéncia \& Saude Coletiva. 2008;13(5):1409-1420.

89. Tragtenberg M. Administração, poder e ideología. São Paulo: Cortez Editora; 1989.

90. Perrow C. The analysis of goals in complex organizations. American Sociological Review. $1961 ; 26(6): 854$

91. Testa M. Análisis de instituciones hipercomplejas. En: Agir em saúde: um desafio para o público. São Paulo: Hucitec, Lugar Editorial; 1997.
92. Freeman HE, Levine S, Reeder LG. Manual de sociología médica. Mexico: Secretaría de Salud, Fondo de Cultura Economica; 1998.

93. El complejo industrial-militar según Eisenhower. En: Carpetas docentes de Historia [Internet]. Buenos Aires: Facultad de Humanidades y Ciencias de la Educación, Universidad Nacional de La Plata; 2017 [citado 11 ago 2017]. Disponible en: https://tinyurl.com/y73fg32t.

94. Meyers HB. The medical industrial complex. Fortune. 1970;81(1):90-91

95. Grimal P. Diccionario de mitología griega y romana. Buenos Aires: Paidós; 2014.

96. García JC. Medicina y sociedad: las corrientes de pensamiento en el campo de la salud. En: García JC, Nunes ED, Franco S, Rodríguez MI. Pensamiento social en salud en América Latina. Washington DC: Interamericana McGraw Hill, OPS; 1994.

97. Nogueira RP. La salud que hace mal: un estudio alrededor del pensamiento de Ivan Illich. Buenos Aires: Lugar Editorial; 2008.

98. Silverman M, Lee P. Píldoras, ganancias y política. México DF: Siglo XXI Editores; 1983.

99. Mendonça ALO, Camargo Jr KR. Complexo médico-industrial/financeiro: os lados epistemológico e axiológico da balança. Physis. 2012;22(1):215-238.

100. Iriart C. Capital financiero versus complejo médico-industrial: los desafíos de las agencias regulatorias. Ciência e Saúde Coletiva. 2008;13(5):1619 1626.

101. Iriart C, Merhy E. Disputas inter-capitalistas, biomedicalización y modelo médico hegemónico. Interface - Comunicação, Saúde, Educação. doi: 10.1590/1807-57622016.0808.

102. Vianna C. Política tecnológica e evoluçao industrial no setor da saude. En: Guimarães $R$, Tavares RAW. Saúde e Sociedade no Brasil: anos 80 Rio de Janeiro: Relume Dumara; 1994. p. 209-252.

103. Santos MA, Passos SR. Comércio internacional de serviços e complexo industrial da saúde: implicações para os sistemas nacionais de saúde. Cadernos de Saúde Pública. 2010;26(8):1483-1493.

104. Angell M. La verdad acerca de la industria farmacéutica: cómo nos engaña y qué hacer al respecto. Bogotá: Grupo Editorial Norma; 2006.

105. Homedes N, Ugalde A. Ética y ensayos clínicos en América Latina. Buenos Aires: Lugar Editorial; 2013. 
106. Castiel L, Povoa Conte E. Dr. Sackett \& "Mr Sacketeer"...: encanto y desencanto en el reino de la expertise en medicina basada en evidencia. Cuadernos Medico Sociales. 2001;(80):37-49.

107. Uchôa SA, Camargo Jr KR. Os protocolos e a decisão médica: medicina baseada em vivências e ou evidências? Ciência e Saúde Coletiva. 2010;15(4):2241-2249.

108. Justich PR. ¿Medicina basada en el mercado o medicina basada en el paciente? Archivos Argentinos de Pediatría. 2015;113(2):146-153.

109. Churchill LR, Perry JE. Introduction. Journal of Law, Medicine \& Ethics. 2015;42(4):408-411.

110. Jupiter J, Burke D. Scott's parabola and the rise of the medical-industrial complex. Hand. 2013;8(3):249-252.

111. Das A. Pharmaceutical industry and the market: The case of Prozac and other antidepressants. Asian Journal of Psychiatry. 2011;4(1):14-18.

112. Conrad P. The medicalization of society: on the transformation of human conditions into treatable disorders. Baltimore: The Johns Hopkins University Press; 2007.

113. Whitaker R. Anatomia de uma epidemia: Pílulas mágicas, drogas psiquiátrica e o aumento assomborso da doença mental. Rio de Janeiro: Fiocruz, Cebes; 2017.

114. Schatman M. The medical-industrial complex and conflict of interest in pain education. Pain Medicine. 2011;12(12):1720-1712.

115. Schofferman J. The medical-industrial complex, professional medical associations, and continuing medical education. Pain Medicine. 2011;12: 1713-1719.

116. Brody $\mathrm{H}$. Pharmaceutical industry financial support for medical education: Benefit, or undue influence? Journal of Law, Medicine \& Ethics. 2009;37(3):451-460.

117. Campbell E, Zinner D. Disclosing industry relationships-Toward an improved federal research policy. New England Journal of Medicine. 2010;363(7):604-606.

118. Jones J, McCullough LB, Richman BW. Consultation or corruption?: The ethics of signing on to the medical-industrial complex. Journal of Vascular Surgery. 2006;43(1):192-195.

119. Sahm S. On markets and morals-(re-)establishing independent decision making in healthcare: a reply to Joao Calinas-Correia. Medicine, Health Care and Philosophy. 2013;16(2):311-315.

120. Calinas-Correia JC. Big pharma: a story of success in a market economy. Medicine Health Care and Philosophy. 2013;16(2):305-309.

121. Gøtzsche PC. Medicamentos que matan y crimen organizado: cómo las grandes farmacéuticas han corrompido el sistema de salud. 7a ed. Barcelona: Los Libros del Lince; 2017.

122. Gøtzsche PC. A moral governance crisis: the growing lack of democratic collaboration and scientific pluralism in Cochrane [Internet]. 2018 [citado 14 sep 2018]. Disponible en: https:// tinyurl.com/y8qqep35.

123. Lin T, Cenicola T. Arnold S Relman and Marcia Angell [Internet]. 2012 [citado 10 mar 2018]. Disponible en: https://tinyurl.com/yamol6ny.

124. Belmartino S. Nuevas reglas para la atención médica en Argentina: ¿quién será el árbitro? Buenos Aires: Lugar Editorial; 1999.

125. Mendes-Gonçalves RB. Saúde, sociedade \& história. São Paulo: Hucitec; 2017.

126. Schraiber L. O médico e seu trabalho: Limites da liberdade. São Paulo: Hucitec; 1993.

127. Engeströn Y. Los estudios evolutivos del trabajo como punto de referencia de la teoría de la actividad: el caso de la práctica médica de la asistencia básica. En: Chaiklin S, Lave J, (comps.). Estudiar las prácticas: perspectivas sobre actividad y contexto. Buenos Aires: Amorrortu; 1996. p. 78118.

128. Sennett R. El artesano. Barcelona: Anagrama; 2010.

129. Marx C. Elementos fundamentales para la crítica de la economía política (los Grundrisse) 1857-1858. México DF: Siglo XXI Editores; 2007.

130. Castoriadis C. As encruzilhadas do labirinto. Rio de Janeiro: Paz e Terra; 1987.

131. Heidegger M. Filosofía, ciencia y técnica. Santiago de Chile: Editorial Universitaria; 2017.

132. Burneo Salazar C. Cuerpo en el interregno: Descartes padre. En: Crespo JP. Vértigo: ocho ensayos de temas escabrosos. Quito: Turbina; 2016. p. 67-79.

133. Intuitive. Da Vinci robotic assisted surgical systems [Internet]. 2017 [citado 23 dic 2017]. Disponible en: https://www.intuitive.com/en. 
134. Testa M. Visión desde la cama del paciente. En: Cohen H, Santos B, Saidón O. Políticas en salud mental. Buenos Aires: Lugar Editorial; 1994. p. 175-187.

135. Relman A. On breaking one's neck. The New Yorks Review of Books [Internet]. 2 jun 2014 [citado 19 jun 2017]. Disponible en: https:// tinyurl.com/ycxc3tsn.

136. Cohen Dabah E. Glosario Walter Benjamin: conceptos y figuras. México DF: UNAM; 2016.

137. Belmartino S. Corporación médica y poder en salud: Argentina, 1920-1945. Rosario: Centro de Estudios Sanitarios y Sociales; 1988.

138. Samaja J. Epistemología de la salud reproducción social, subjetividad y transdisciplina. Buenos Aires: Lugar Editorial; 2004.

139. Samaja J. Epistemología y metodología: elementos para una teoría de la investigación científica. 3a ed. Buenos Aires: Eudeba; 1993.

140. Sigerist H. Los grandes médicos: historia biográfica de la medicina. Barcelona: Ediciones AVE; 1949.

141. Ayres JRCM. Cuidado: trabalho e interação nas práticas de saúde. Rio de Janeiro: CEPESC, IMS/UERJ, Abrasco; 2009.

142. Matus C. Teoría del juego social. Remedios de Escalada: Ediciones de la UNLa; 2007.
143. Huizinga J. Homo ludens. Buenos Aires: Alianza Editorial; 1968.

144. Geertz C. La interpretación de las culturas. Barcelona: Gedisa; 1973.

145. Spinelli H. Volver a pensar en salud: programas y territorios. Salud Colectiva. 2016;12(2):149-171.

146. Dawson B. Informe de Dawson sobre el futuro de los servicios médicos y afines 1920 Washington DC: OPS; 1964.

147. Lord Dawson's Interim report on the future provision of medical and allied services 1920 was published in May 1920. Policy Navigator [Internet]. 1920 [citado 24 dic 2017]. Disponible en: https://tinyurl.com/yalvdny8.

148. Fee E, Brown T. Making medical history: the life and times of Henry E. Sigerist. Baltimore: Johns Hopkins University Press; 1997.

149. Sigerist $H$. Hitos en la historia de la salud pública. México DF: Siglo XXI Editores; 1987.

150. Bissot Alvarez A. Dr. José Renán Esquivel Oses [Internet]. Panamá: Hospital del Niño Dr. José Renán Esquivel; 2016 [citado 24 feb 2018]. Disponible en: https://tinyurl.com/ybg39zqo.

151. Weber M. A ética protestante e o "espirito" do capitalismo. São Paulo: Livraria Pioneira Editora; 1992. 